\title{
One-Pot Combination of Metal- and Bio-Catalysis in Water for the Synthesis of Chiral Molecules
}

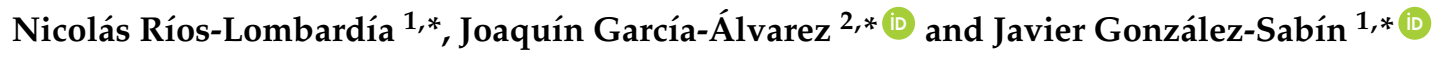 \\ 1 EntreChem SL, Vivero Ciencias de la Salud, Santo Domingo de Guzmán, 33011 Oviedo, Spain \\ 2 Laboratorio de Compuestos Organometálicos y Catálisis (Unidad Asociada al CSIC), \\ Centro de Innovación en Química Avanzada (ORFEO-CINQA), Departamento de Química Orgánica e \\ Inorgánica, Universidad de Oviedo, E-33006 Oviedo, Spain \\ * Correspondence: nicolas.rios@entrechem.com (N.R.-L.); garciajoaquin@uniovi.es (J.G.-A.); \\ jgsabin@entrechem.com (J.G.-S.); Tel.: +34-985-103-464 (J.G.-A.); +34-985-259-021(J.G.-S.)
}

Received: 22 January 2018; Accepted: 8 February 2018; Published: 10 February 2018

\begin{abstract}
During the last decade, the combination of different metal- and bio-catalyzed organic reactions in aqueous media has permitted the flourishing of a variety of one-pot asymmetric multi-catalytic reactions devoted to the construction of enantiopure and high added-value chemicals under mild reaction conditions (usually room temperature) and in the presence of air. Herein, a comprehensive account of the state-of-the-art in the development of catalytic networks by combining metallic and biological catalysts in aqueous media (the natural environment of enzymes) is presented. Among others, the combination of metal-catalyzed isomerizations, cycloadditions, hydrations, olefin metathesis, oxidations, C-C cross-coupling and hydrogenation reactions, with several biocatalyzed transformations of organic groups (enzymatic reduction, epoxidation, halogenation or ester hydrolysis), are discussed.
\end{abstract}

Keywords: one-pot processes; cascade reactions; tandem catalysis; metal-catalysis; biocatalysis; enantioselective; water

\section{Introduction}

Challenges faced by today's synthetic organic chemists when trying to access highly-functionalized small molecules are evolving rapidly due to the new safety and economic needs imposed by our society [1]. In this sense, finding new ways of perfecting (i) chemo-, regio- and stereo-selectivities, (ii) functional group tolerance and (iii) reaction yields, have been always present, but, with the end of last century, a new awareness arose to produce chemicals and materials also under mild reaction conditions [2]. Thus, and for a successful proposal of new chemical processes, synthetic chemists try to design reactions that should: (i) be safe (even when scaled-up); (ii) take place under mild reactions conditions (room temperature and the absence of a protecting atmosphere are desirable); (iii) be catalytic [3]; and (iv) be performed using inexpensive and non-dangerous solvents [4,5] (i.e., water). Bearing in mind these challenges, the use of enzymes or whole microorganisms (nature's catalysts, which are usually non-toxic, biodegradable and biocompatible) has experienced a spectacular growth for the synthesis of small organic molecules containing chiral units [6] (which are widespread within the fine chemical industry) under physiological conditions, thus achieving numerous safety and economic benefits. Recent years have also seen an impressive advance in multi-enzymatic systems of remarkable complexity [7-10], which try to emulate Nature, as living organisms use a great number of enzymatic cascades (in different metabolic pathways) employing the same reaction media (i.e., the cytosol). Thus, the in vitro development of these one-pot asymmetric multi-catalytic enzymatic reactions permits the synthesis of valuable target molecules under practical and economic advantages 
(for example, minimization of waste production, time- and energy-consuming and tedious purification steps) [11].

While greater attention has been placed on the development of the aforementioned multi-catalytic enzymatic reactions [7-10], the combination of two different catalytic disciplines (for example chemo- and bio-catalysis) is still in its infancy. Among the two possible combinations (organo-/bio-catalysis [12] and metal-/biocatalysis), the potential of assembling transition-metal-catalyzed reactions with enzymatic transformations remains particularly appealing as both catalytic methodologies: (i) present important differences in terms of productivity, reactivity and selectivity; and (ii) constitute two of the most important pillars in the toolbox of synthetic organic chemistry [13]. However, the vast majority of examples reported in this field (e.g., dynamic kinetic resolution (DKRs) by combining racemizing metal catalysts with an enzymatic transformation) rely on the use of volatile organic solvents (VOCs; e.g., toluene, THF, diethyl ether, etc.) [14-19] in order to avoid the degradation usually exhibited by the transition-metal catalysts in aqueous solutions (the natural environment of enzymes). Nevertheless, and during the last decade, a plethora of studies has demonstrated the possibility to perform metal-catalyzed organic reactions in water, finding, in some cases, an enhancement of the rate or a change in the selectivity of a given reaction [20]. Thus, this gradual emergence of metal-catalyzed transformations in water along with the advances in protein engineering to produce more stable enzymes has boosted the search for new catalytic systems, merging the advantages of both catalytic worlds (metal- and bio-catalysis) in water. At this point, we should point out that these catalytic networks imply important challenges [21,22], like: (i) metaland bio-catalyst compatibility and stability; (ii) undesired cross-reactivity; (iii) the employment of different catalytic reaction conditions (basically related to temperature and concentration); and (iv) the use of different co-solvents, co-catalysts or co-factors. Thus, this review intends to provide a general overview, including our own investigations and contributions by other research groups, of the field of metal- and bio-catalyzed organic reactions in water, with particular focus on work reported during the last three years [23]. The contents of this review are organized into six main sections according to the nature of the metal-catalyzed organic reaction.

\section{Metal-Catalyzed Isomerization of Unsaturated Organic Substrates Coupled with Enzymatic Aminations, Reductions or Hydrolyses}

Metal-catalyzed isomerizations or cycloisomerizations of unsaturated organic substrates are good examples of atom economic processes [24-26] as they usually proceed with a total mass transfer from starting reagents to products. Thus, in this section, we describe the modular combination of: (i) the $\mathrm{Ru}(\mathrm{IV})$-catalyzed redox isomerization of allylic alcohols with the enantioselective bioamination or bioreduction of the transiently-formed prochiral ketones [27,28]; (ii) the Pd(II)- or $\mathrm{Au}$ (III)-catalyzed cycloisomerization/hydrolysis of alkynes containing a tethered nucleophile as the substituent with a concomitant bioreduction (ketoreductase (KRED)) of the in situ generated carbonyl compounds [29]; and (iii) the tandem esterase- or lipase-mediated hydrolysis of allenyl acetates followed by the $\mathrm{Au}(\mathrm{I})$-catalyzed cyclization of the corresponding allenols to produce chiral tetrahydrofurans [30].

\subsection{Combination of $R u(I V)$-Catalyzed Redox Isomerization of Allylic Alcohols and Bioamination or Bioreduction in Aqueous Media}

The metal-catalyzed redox isomerization of allylic alcohols, which involves the migration of a $C=C$ bond followed by the spontaneous tautomerization of the transiently-formed enol [31-35], is an elegant and powerful synthetic route for the production of saturated carbonyl compounds in quantitative yields. In particular, a family of bis(allyl)-ruthenium(IV) complexes (1-3; Figure 1) were described as active and selective catalysts for the isomerization of a wide variety allylic alcohols in water, under mild reaction conditions (temperature from $\mathrm{rt}$ to $40{ }^{\circ} \mathrm{C}$ ), and in the absence of co-catalyst [36-39], which are ideal conditions for further biotransformations. 


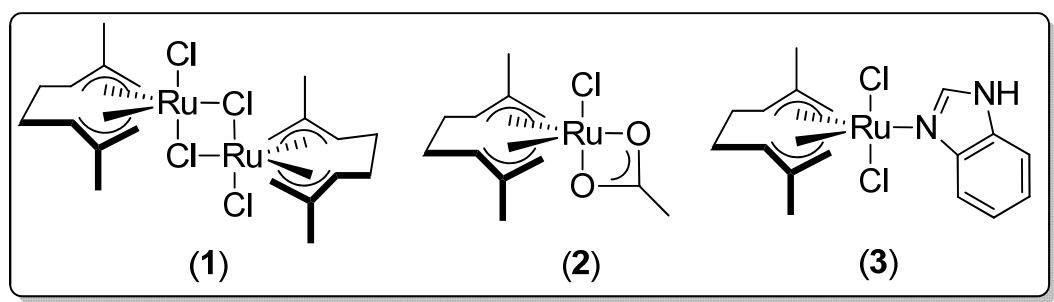

Figure 1. Highly-efficient and selective bis(allyl)-ruthenium(IV) catalysts (1-3) for the redox isomerization of allylic alcohols in water and under mild reaction conditions.

Thus, the starting point of our investigations, devoted to the combination of metal- and bio-catalysts in aqueous media, was the design of a one-pot tandem process through the assembly of the $\mathrm{Ru}(\mathrm{IV})$-catalyzed redox isomerization of allylic alcohols with a $\omega$-transaminase ( $\omega$-TA)-mediated bioamination reaction [27]. Initially, the catalytic activity of Complexes 1-3 (Figure 1) was evaluated in the redox isomerization of racemic allylic alcohols into prochiral ketones (Scheme 1), but in the conditions imposed by the second step of the process, namely the employment of a phosphate buffer solution containing ${ }^{i} \mathrm{PrNH}_{2}$ (as a source for the amino group). Pleasantly, we found that under these "bio-conditions", Complex 3 was an efficient and selective catalyst for the isomerization reaction $\left(50{ }^{\circ} \mathrm{C}\right.$ and $1 \mathrm{~mol} \%$ in $[\mathrm{Ru}]$ ) yielding the desired ketones in almost quantitative yields (Scheme 1). Next, we studied separately the second step, namely the bioamination of the aforementioned carbonyl compounds mediated by $\omega$-TAs, but in the presence of catalytic amounts of the bis(allyl)-Ru(IV) Complex 3. This enzymatic screening of commercially available $\omega$-TAs enabled identifying highly-efficient biocatalysts, which produced both enantiomers of each amine in almost quantitative conversion and excellent enantiomeric excess, even in the company of the ruthenium Catalyst 3.

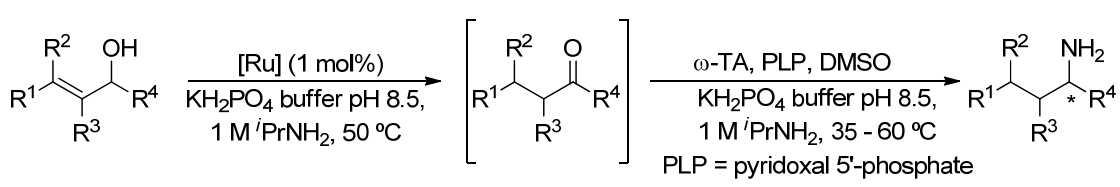

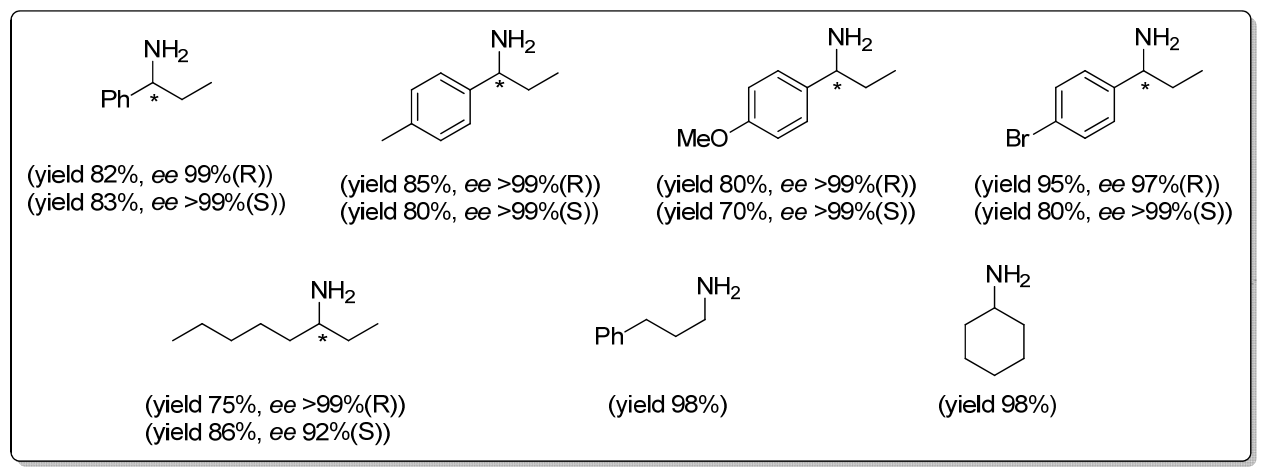

Scheme 1. $\mathrm{Ru}(\mathrm{IV})$-catalyzed isomerization of a variety of allylic alcohols and sequential bioamination promoted by $\omega$-transaminases ( $\omega$-TAs).

With both individual steps optimized, the compatibility studies revealed a strong inhibition exerted by the enzymatic system on the metal Catalyst 3 . However, this drawback could be easily circumvented just by adopting a one-pot/two-step methodology (Scheme 1). Thus, once the initial $\mathrm{Ru}(\mathrm{IV})$-catalyzed isomerization of the desired allylic alcohol was completed in the buffer solution, the corresponding $\omega$-TA and its co-factor (PLP, pyridoxal 5'-phosphate) were added to the reaction media. This methodology enabled transforming racemic allylic alcohols into the corresponding enantiopure saturated amines, without the need for any halfway isolation or purification steps. 
Trying to move one step forward in the design of real concurrent chemoenzymatic one-pot processes, in which the metal-catalyst and the enzyme work together from the beginning of the catalytic reaction, we decided to explore commercially available ketoreductases (KREDs) as alternative biocatalysts [40]. Again, we firstly tested the catalytic activity of the aforementioned bis(allyl)-ruthenium(IV) Complexes 1-3 (Figure 1) in the isomerization of a set of allylic alcohols in the medium required by KREDs (phosphate buffer containing ${ }^{\mathrm{i}} \mathrm{PrOH}$ as the hydrogen source) [28]. In this case, only the acetate- $\mathrm{Ru}(\mathrm{IV})$ Complex 2 retained its high catalytic activity ( $99 \%$ conversions in $1-10 \mathrm{~h}$ ) and selectivity, as undesired simultaneous reduction of the obtained ketones (through Ru-catalyzed transfer hydrogenation [41]) was not observed. In this case, the compatibility studies unveiled the same catalytic activity for Complex 2 (99\% conversion in the desired ketones) in the presence of KREDs and their co-factor NADPH. Similarly and as previously detected with $\omega$-TAs [27], no inhibition was observed in the biocatalytic system when the ruthenium catalyst was present in the reaction media. After both steps (metal- and bio-catalysis) were independently optimized and several issues (such as reaction medium optimization (i.e., percentage of ${ }^{\mathrm{i}} \mathrm{PrOH}, 15 \% v / v$ ), concentration of co-factor, metal-catalyst loading $(5 \mathrm{~mol} \%)$ and reaction temperature $\left(30^{\circ} \mathrm{C}\right)$ ) were addressed (Scheme 2$)$, we were able to develop, for the first time, a genuine one-pot concurrent process where the metal Catalyst 2 and the biocatalyst coexist from the beginning in aqueous medium, giving rise to enantiopure saturated alcohols starting from racemic allylic alcohols.
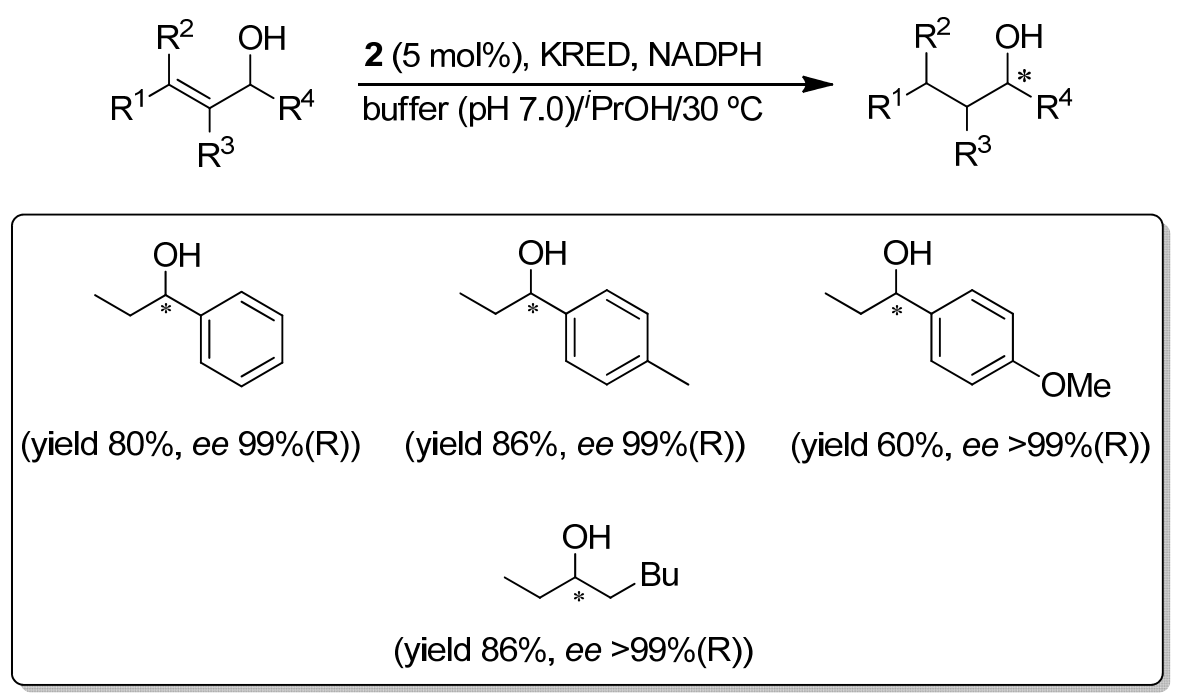

Scheme 2. Concurrent (one-pot cascade) metal-catalyzed isomerization/enzymatic reduction of racemic allylic alcohols by combining ruthenium Complex 2 and ketoreductases (KREDs).

Prior to our work, Bergman, Raymond, Toste and co-workers reported a non-chiral methodology that combines the $\mathrm{Ru}(\mathrm{II})$-catalyzed isomerization of the allylic alcohol (2-propenol) into propanal with a subsequent bioreduction process promoted by horse-liver alcohol dehydrogenase (HL-ADH) [30]. In this context, the authors incorporated the cationic ruthenium complex $\left[\mathrm{RuCp}(\mathrm{MeCN})_{3}\right]^{+}$ into a supramolecular $\left[\mathrm{Ga}_{4} \mathrm{~L}_{6}\right]^{12-}$ tetrahedral assembly $\left(\mathrm{L}=N, N^{\prime}\right.$-bis(2,3-dihydroxybenzoyl)1,5-diaminonaphthalene) and tested the resulting water-soluble host-guest System 4 in the isomerization of the aforementioned allylic alcohol in water [42]. Thus, treatment of 2-propenol with a combo mixture containing (i) the metallic host-guest System 4, (ii) the horse-liver alcohol dehydrogenase (HL-ADH) and (iii) NADPH, yeast formate dehydrogenase (FDH) and sodium formate led to the formation of propanol in $61 \%$ yield after six hours of reaction at $37^{\circ} \mathrm{C}$ (Scheme 3). Finally, it was also demonstrated that neither the enzymatic system, nor the ruthenium catalyst could promote the tandem isomerization/reduction reaction on its own. 

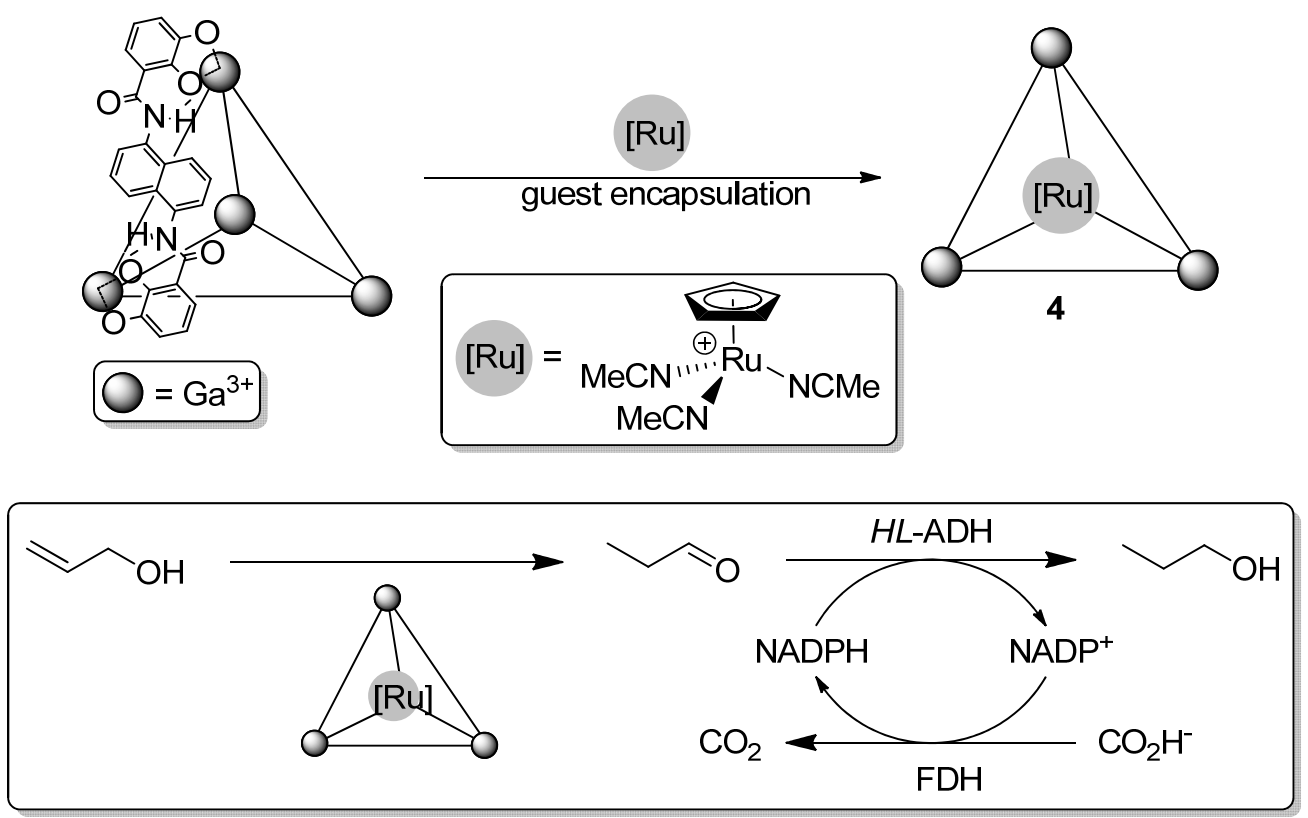

Scheme 3. Synthesis of $\mathrm{Ru}(\mathrm{II})$-host-guest Complex 4 and the design of a tandem isomerization/ bioreduction of the allylic alcohol (2-propenol).

2.2. Assembly of Metal-Catalyzed Cycloisomerization of Allenyl Acetates or Terminal Alkynes with Esterases, Lipases or Ketoreductases in Aqueous Media

In addition to the aforementioned $\left[\mathrm{RuCp}(\mathrm{MeCN})_{3}\right]^{+}$, the cationic metallic fragment $\left[\mathrm{Au}\left(\mathrm{PMe}_{3}\right)\right]^{+}$ was also successfully encapsulated in the previously-mentioned host assembly $\left[\mathrm{Ga}_{4} \mathrm{~L}_{6}\right]^{12-}$, giving rise to the gold(I) host-guest Complex 5, which is stable at neutral pH in water (Scheme 4) [30]. In this case, it was found that the supramolecular Complex 5 exhibited an eight-fold rate enhancement when compared with the free gold complex $\left[\mathrm{AuCl}\left(\mathrm{PMe}_{3}\right)\right]$ in the hydroalkoxylation of linear allenyl alcohols (Scheme 4A). Bearing this result in mind, it was hypothesized that a prior enzymatic hydrolysis of allenyl acetates (promoted by lipases or esterases) could produce in situ the desired allenols. Following this idea, the tandem acetate hydrolysis/hydroalkoxylation reaction of allenyl acetates was examined with a variety of esterases (rabbit liver esterase, hog liver esterase and horse liver esterase) or lipases (Mucor miehei lipase, Amano lipase) and the supramolecular Complex 5 (Scheme 4B), being able to achieve quantitative yields of the final substituted tetrahydrofuran when rabbit liver esterase was employed [31]. To further explore their hypothesis, the authors designed a tandem enzymatic kinetic resolution/hydroalkoxylation reaction finding enantiomeric excesses ranging from $46 \%$ (hog liver esterase) to $96 \%$ (Amano lipase). Additionally, some kinetic experiments revealed that supramolecular Complex 5 had little effect on the studied enzymes, while free $\left[\mathrm{AuCl}\left(\mathrm{PMe}_{3}\right)\right]$ eroded the catalytic activity of the esterases or lipases. 

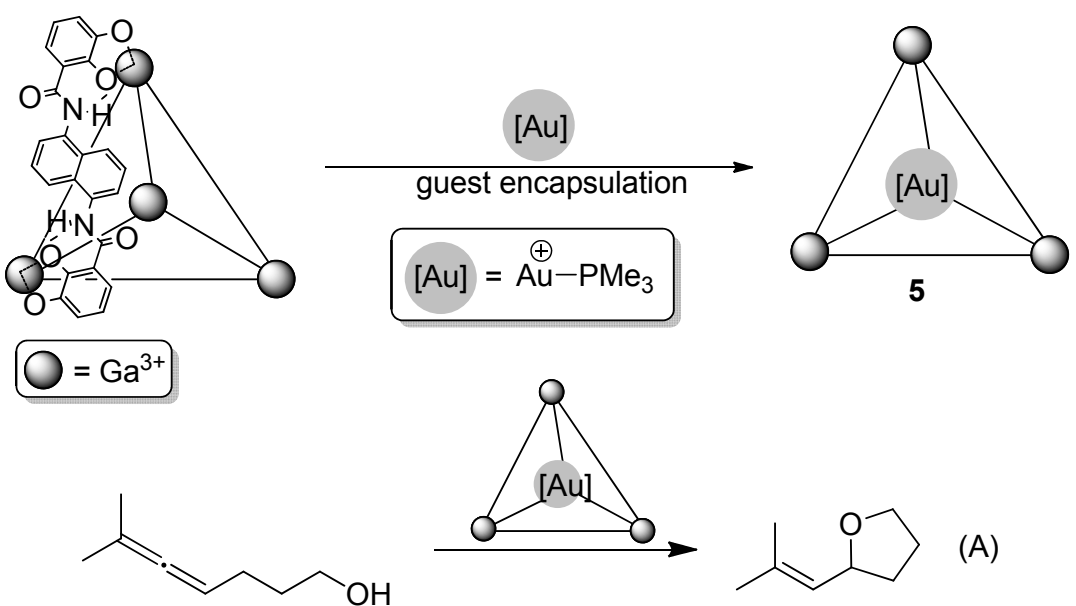

eight-fold rate enhancement when compared with $\left[\mathrm{AuCl}\left(\mathrm{PMe}_{3}\right)\right]$

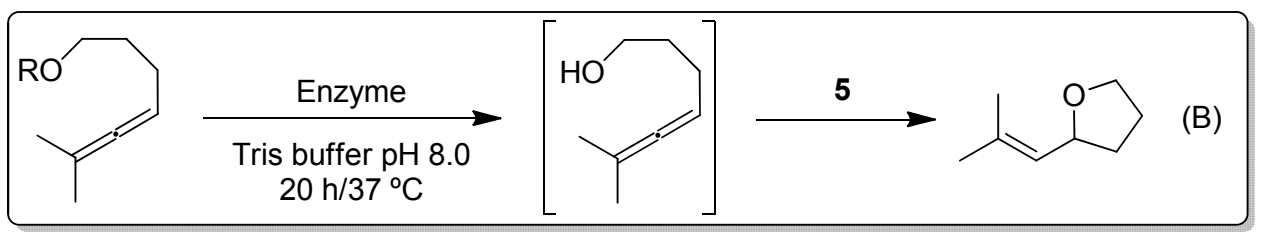

Scheme 4. Synthesis of $\mathrm{Au}(\mathrm{I})$-host-guest Complex 5 and design of tandem esterase/lipase acetate hydrolysis (A) and Au(I)-catalyzed hydroalkoxylation of allenyl acetates (B).

Inspired by these results and with the aim of expanding the synthetic scope of one-pot cascade processes involving metal- and bio-catalytic events in aqueous media, we turned our attention to the possible combination of the metal-catalyzed cycloisomerization of alkynes containing a tethered nucleophile $(\mathrm{NuH}$; followed by the spontaneous hydrolysis of the transiently-formed five-membered heterocycles) with a concomitant bioreduction of the transiently-formed prochiral ketones without the need for any halfway isolation or purification steps (Scheme 5) [29].

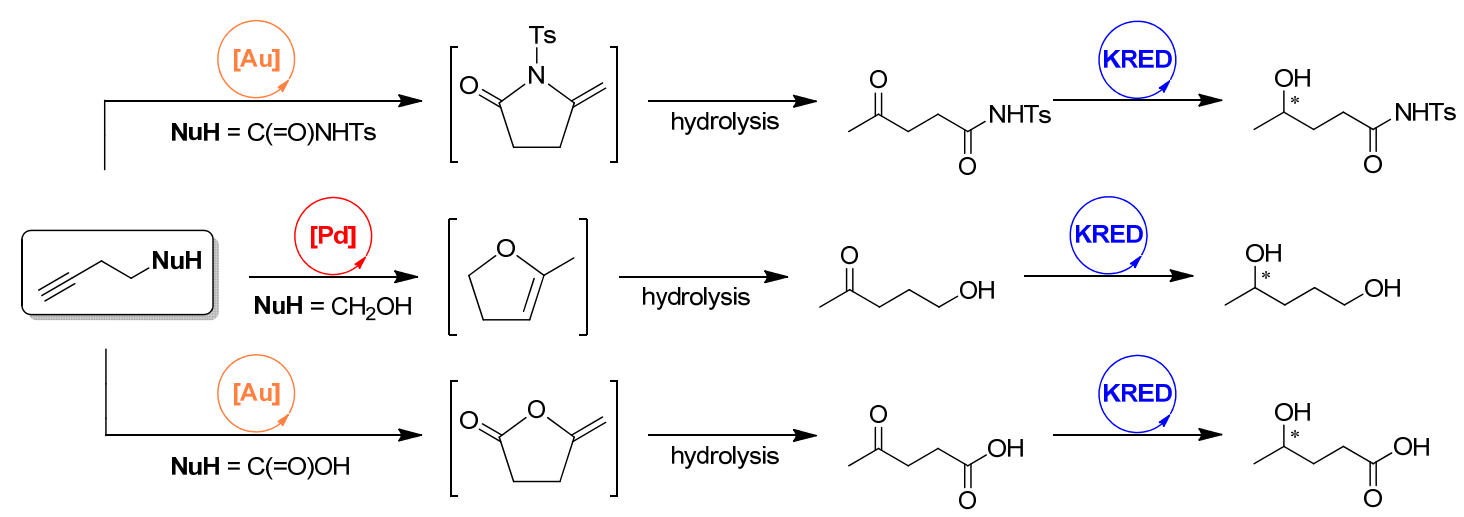

Scheme 5. One-pot conversion of alkynyl amides, alkynols or $\gamma$-alkynoic acids into chiral $\gamma$-hydroxy-carbonyl compounds.

Thus, we started our investigations by exploring the $\mathrm{Pd}(\mathrm{II})$-catalyzed cycloisomerization of 4-pentyn-1-ol into 5-methyl-2,3-dihydrofuran in water as the solvent at $30{ }^{\circ} \mathrm{C}$ and under aerobic conditions. However, and instead of the expected dihydrofuran, we observed the quantitative formation of 5-hydroxy-2-pentanone (via formal hydration of the $\mathrm{C} \equiv \mathrm{C}$ bond) when 
the iminophosphorane-Pd(II) Complex 6 was used as the catalyst (Scheme 6). The subsequent combination of this subrogated hydration process with a concomitant bioreduction step promoted by KREDs allowed us to obtain the corresponding 1,4-pentanediol in good yields (up to 90\%) and excellent enantiomeric excesses for both possible enantiomers after $24 \mathrm{~h}$ of reaction (Scheme 6) [29]. At this point, it is important to note that the reaction media coming from the metal-catalyzed reaction (containing the $\mathrm{Pd}(\mathrm{II})$-Complex 6) was employed directly to feed the biocatalyst. Finally, a triple metal-/bio-/bio-catalyzed reaction was established by combining the aforementioned synthesis of chiral 1,4-pentandiol with a laccase/(2,2,6,6-Tetramethylpiperidin-1-yl)oxyl) TEMPO-catalyzed oxidation reaction giving rise to both antipodes of $\gamma$-valerolactone in quantitative yield and excellent enantiomeric excess [43].

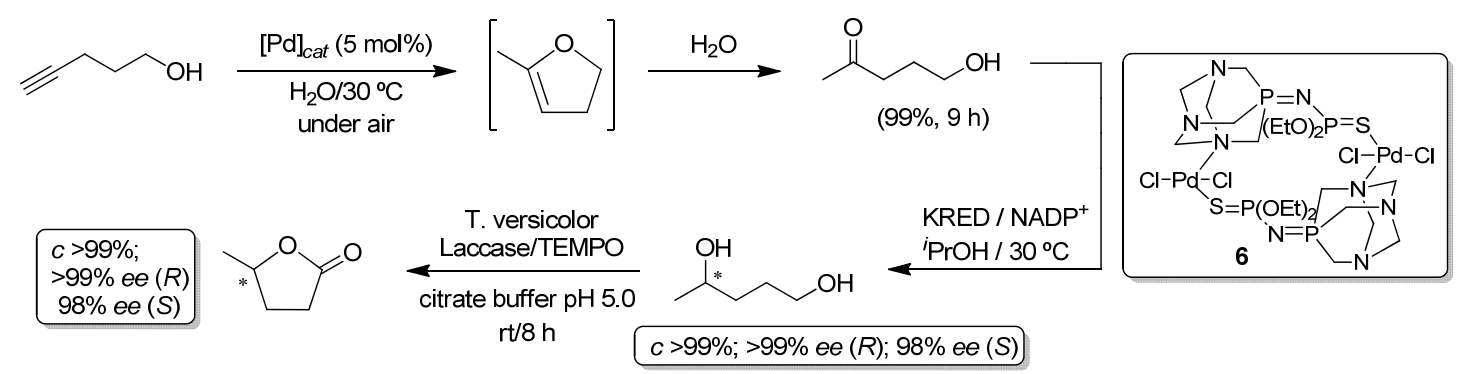

Scheme 6. One-pot synthesis of 1,4-pentanediol and concomitant oxidation triggered by the catalytic system laccase/TEMPO towards enantiopure $\gamma$-valerolactone.

Metal-catalyzed cycloisomerization of $\gamma$-alkynoic acids provides an efficient entry to cyclic enol-lactones [44-47], which could easily undergo a hydrolysis reaction yielding acyclic keto-acids as products [48]. Following the methodology described above, the $\mathrm{Au}(\mathrm{III})$-catalyzed cycloisomerization/hydrolysis of 4-pentynoic acid into levulinic acid was explored (Scheme 7) [49-51]. In this case, the best results were obtained when $\mathrm{KAuCl}_{4}$ was used as the catalyst $(5 \mathrm{~mol} \%)$ at $50{ }^{\circ} \mathrm{C}$ in water (the use of other gold (i.e., [ $\mathrm{AuCl}(\mathrm{SMe} 2)]$ ) or palladium (complex 6) catalysts and/or lower reaction temperatures $\left(30^{\circ} \mathrm{C}\right)$ yielded mixtures of products containing both cyclic enol-lactone and levulinic acid). Next, we focused on the design of a new one-pot process in which the obtained levulinic acid could be enantioselectively reduced by KREDs, employing directly the reaction media coming from the $\mathrm{Au}(\mathrm{III})$-catalyzed reaction (Scheme 7) [29]. Unfortunately, $\mathrm{KAuCl}_{4}$ eroded the catalytic activity of the biocatalyst, giving rise to an incomplete reduction of levulinic acid (50\% maximum). This shortcoming was easily by-passed just by the addition of a coordinating solvent (i.e., DMSO in a $5 \% v / v$ ) to the reaction media, rendering the enantiopure $\gamma$-hydroxyvaleric acid in quantitative yield, employing a one-pot metal/biocatalyzed procedure.

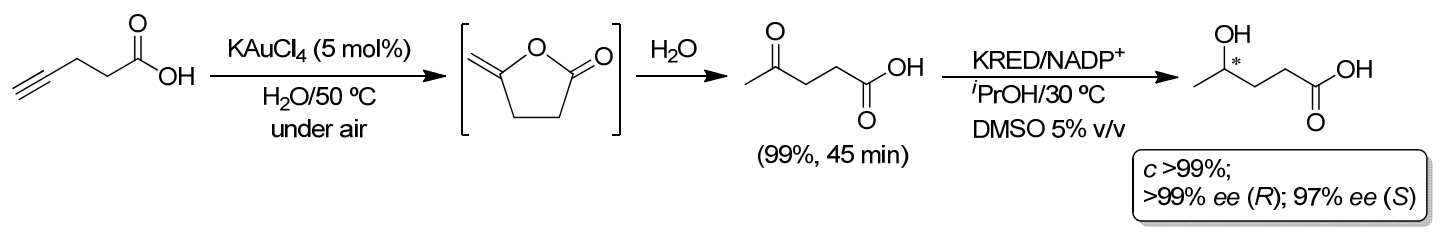

Scheme 7. Enantioselective one-pot conversion of 4-pentynoic acid into $\gamma$-hydroxyvaleric acid in aqueous media through a chemoenzymatic cycloisomerization/hydrolysis/bioreduction process.

Finally, this one-pot protocol (cycloisomerization/hydrolysis/bioreduction of alkynes) was extended to other tethered nucleophiles, namely the conversion of alkynyl amides into the corresponding $\gamma$-keto amides [52], through the hydrolysis of the transiently-formed cyclic alkylidene lactam (Scheme 8A) [53]. In this case, the cycloisomerization/hydrolysis of $N$-tosylpent-4-ynamide could be effectively accomplished by $\mathrm{KAuCl}_{4}(5 \mathrm{~mol} \%)$ in water at $50{ }^{\circ} \mathrm{C}$, yielding the corresponding 
4-oxo- $N$-tosylpentanamide in quantitative yield after $5 \mathrm{~h}$ of reaction [29]. However, in this particular case, only one KRED was able to give rise to the desired $\gamma$-hydroxy amide in good yield (96\%) and excellent enantiomeric excess $(99 \%)$. This unexpected setback could be straightforwardly eluded by designing an intermolecular cascade cyclization process between 4-pentynoic acid and a variety of functionalized anilines, through initial $\mathrm{Au}(\mathrm{III})$-catalyzed cycloisomerization of the alkynoic acid and simultaneous nucleophilic aperture of the transiently-obtained cyclic enol-lactone by the aromatic amine under neat conditions (Scheme 8B). Lastly, the obtained $\gamma$-keto amides (via the cycloisomerization/aminolysis procedure) were successfully transformed into the corresponding enantiopure $\gamma$-hydroxy amides by adding KREDs to the reaction media [29].

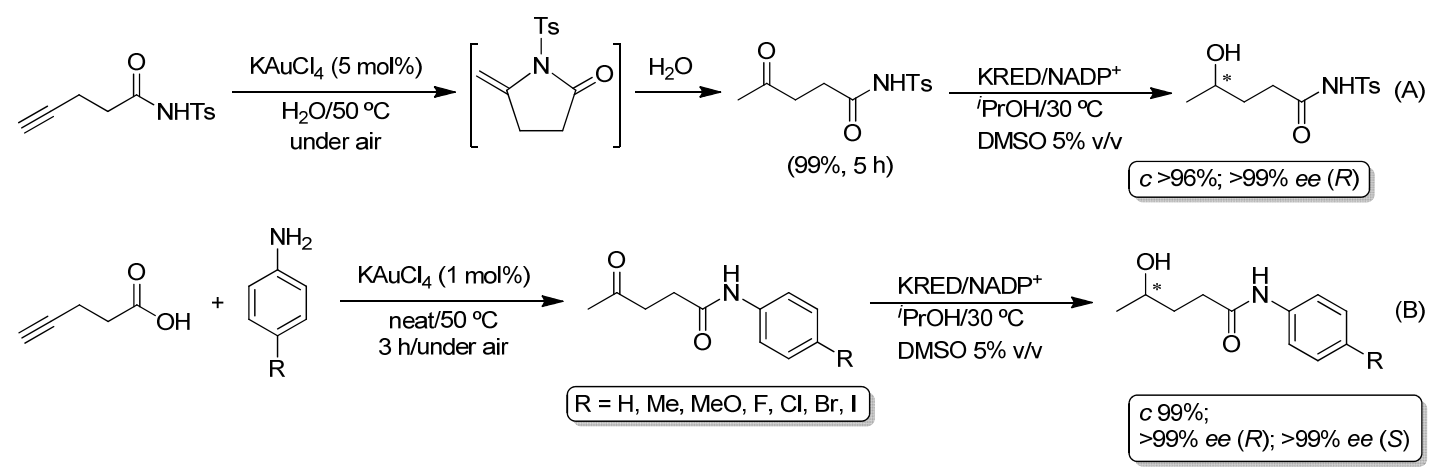

Scheme 8. (A) Enantioselective one-pot conversion of $N$-tosylpent-4-ynamide into $\gamma$-hydroxy amide in aqueous media through a chemoenzymatic cycloisomerization/hydrolysis/bioreduction process.

(B) Chemoenzymatic one-pot conversion of 4-pentynoic acid into enantiopure $\gamma$-hydroxy amides through the combination of metal-catalyzed cycloisomerization/aminolysis and biocatalyzed reactions.

\section{Metal-Catalyzed Hydrogenations Combined with Bioreductions, Hydrogen-Generating Living Microorganisms and Biooxidations}

Metal-catalyzed hydrogenations (both in homogeneous or heterogeneous conditions) are among the most frequently encountered transformations in chemical synthesis [54,55]. In this sense, heterogeneous hydrogenation is mainly used in the production of large-scale chemical products $\left(\mathrm{NH}_{3}, \mathrm{MeOH}\right.$ or cyclohexane, among others), whereas homogeneous hydrogenation is usually employed in the synthesis of fine chemical products (drugs, hormones, fragrances, etc.). Bearing in mind the fact that hydrogenation (as a metal-catalyzed reduction with $\mathrm{H}_{2}$ ) is one of the most studied reactions in aqueous media (since 1960-1970) [56], is not surprising to find in the literature several reports on the combination of metal-catalyzed hydrogenations in water with different biotransformations. Thus, this section covers the progress made in the combination of the aforementioned reactions in water.

\subsection{Combination of Pd-Nanoparticles-Catalyzed Hydrogenation of Azides and Alcohol-Dehydrogenase-Catalyzed Reduction of Azido-Ketones in Water}

Metallic nanoparticles (NPs) have emerged as a sustainable alternative to conventional metallic catalysts, as they usually combine the advantages of heterogeneous (insolubility in the reaction media permits an easy separation) and homogeneous (high surface area increases the contact with the reactants) traditional catalysts [57]. In this sense, Schritttwieser, Kroutil, Hollmann and co-workers explored the activity of lignin-stabilized palladium nanoparticles (Pd-NPs) in the hydrogenation of 2-azido-1-alcohols as a straightforward route to racemic 1,2-amino alcohols by employing $\mathrm{H}_{2}$ (10 bar) as the reducing agent, in a phosphate buffer and at $30^{\circ} \mathrm{C}$, which are the reaction conditions required for the subsequent biocatalytic step (asymmetric bioreduction of 2-azido ketones with ADH) [58]. Having identified the conditions to obtain the desired 1,2-amino alcohols in pure form, the authors next extended their studies to the bioreduction of 2-azido ketones mediated by 79 different 
and commercially-available ADHs and four bacterial ADH (ADH-A from Rhodococcus ruber DSM 44541, Tb-ADH from Thermoanaerobium brockii, Lk-ADH from Lactobacillus kefir and Lb-ADH from Lactobacillus brevis) employing ${ }^{\mathrm{i}} \mathrm{PrOH}$ as the hydrogen source and NADH or NADPH as co-factors. From this parametrization study, ADH-A emerged as the best biocatalyst in terms of reaction yield, enantiomeric excess, enzyme loading and substrate concentration. With both synthetic procedures independently optimized, the authors explored a concurrent one-pot process with both ADH and the Pd-NPs working simultaneously. However, and despite the compatibility of the catalysts in the same reaction media, an important issue was the formation of a side product (2,2-dimethyloxazolidine in $4-10 \%$ ). This drawback could be easily avoided by designing a one-pot/two-step methodology (Scheme 9A) in which the bioreduction is performed under reduced pressure to eliminate acetone of the reaction mixture (byproduct of the ADH-catalyzed reaction). Moreover, a chemoenzymatic three-step transformation was also described in which the organic azide was in situ generated by a halogen-azide exchange reaction in different 1,2-halo-ketones promoted by the system $\mathrm{NaN}_{3} / \mathrm{KI}_{\text {cat }}$ (Scheme 9B). Finally, this three-step methodology was applied for the asymmetric synthesis of the antiviral (HIV) (S)-tembamide.

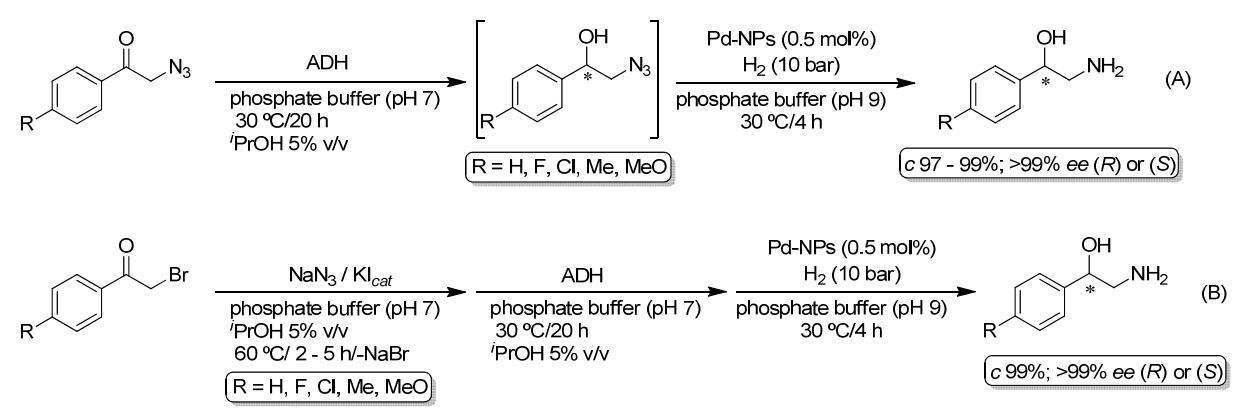

Scheme 9. (A) Chemoenzymatic one-pot/two-step conversion of 2-azido ketones into enantiopure 1,2-amino alcohols through the combination of Pd-NP-catalyzed hydrogenation and asymmetric bioreduction (ADH). (B) Chemoenzymatic one-pot/three-steps conversion of 2-halo ketones into enantiopure 1,2-amino alcohols.

\subsection{Assembly of Pd-Catalyzed Hydrogenation of Olefins and Living-Microorganism- $\mathrm{H}_{2}$-Generation (Escherichia coli) in Aqueous Media}

Going one step further in the combination of both metal-catalyzed hydrogenation reactions and biocatalysis, Balskus and co-workers have demonstrated the possibility to implement a Pd-catalyzed hydrogenation of alkenes in which the hydrogen gas $\left(\mathrm{H}_{2}\right)$ was generated in situ by a living microorganism [59]. Firstly, the authors assayed, as a model reaction, the hydrogenation of the water-soluble alkene caffeic acid catalyzed by the Royer palladium catalyst $[60,61]$ in a reaction media able to allow the growth of Escherichia coli DD-2 (optical density $(\mathrm{OD})=0.4$ ), which is responsible for the production of hydrogen from glucose employing an inducible pathway involving ferredoxin, a pyruvate ferredoxin oxidoreductase and a [Fe-Fe] hydrogenase [62] (Scheme 10A). To boost the in situ hydrogen generation (by increasing the amount of functional [Fe-Fe] hydrogenase generated in cells [63]), both iron and casamino acids were added to the reaction media. Under these optimized conditions, the caffeic acid was quantitatively hydrogenated into the desired alkane (3,4-dihydroxyhydrocinnamic acid) after $18 \mathrm{~h}$ of incubation at $37^{\circ} \mathrm{C}$. Notably, the reaction was scaled up to $1.6 \mathrm{~g}(9 \mathrm{mmol})$ of caffeic acid in just one batch of reaction. Moreover, the process was extended to other functionalized alkenes finding that the metal-/bio-catalytic hydrogenation system tolerates the presence of esters, nitriles, amides or alcohols as substituents in the starting olefins (Scheme 10B). Finally, not only alkenes, but also alkynes (i.e., phenylpropiolic acid) could be successfully reduced into the corresponding alkane (phenylpropanoic acid). 

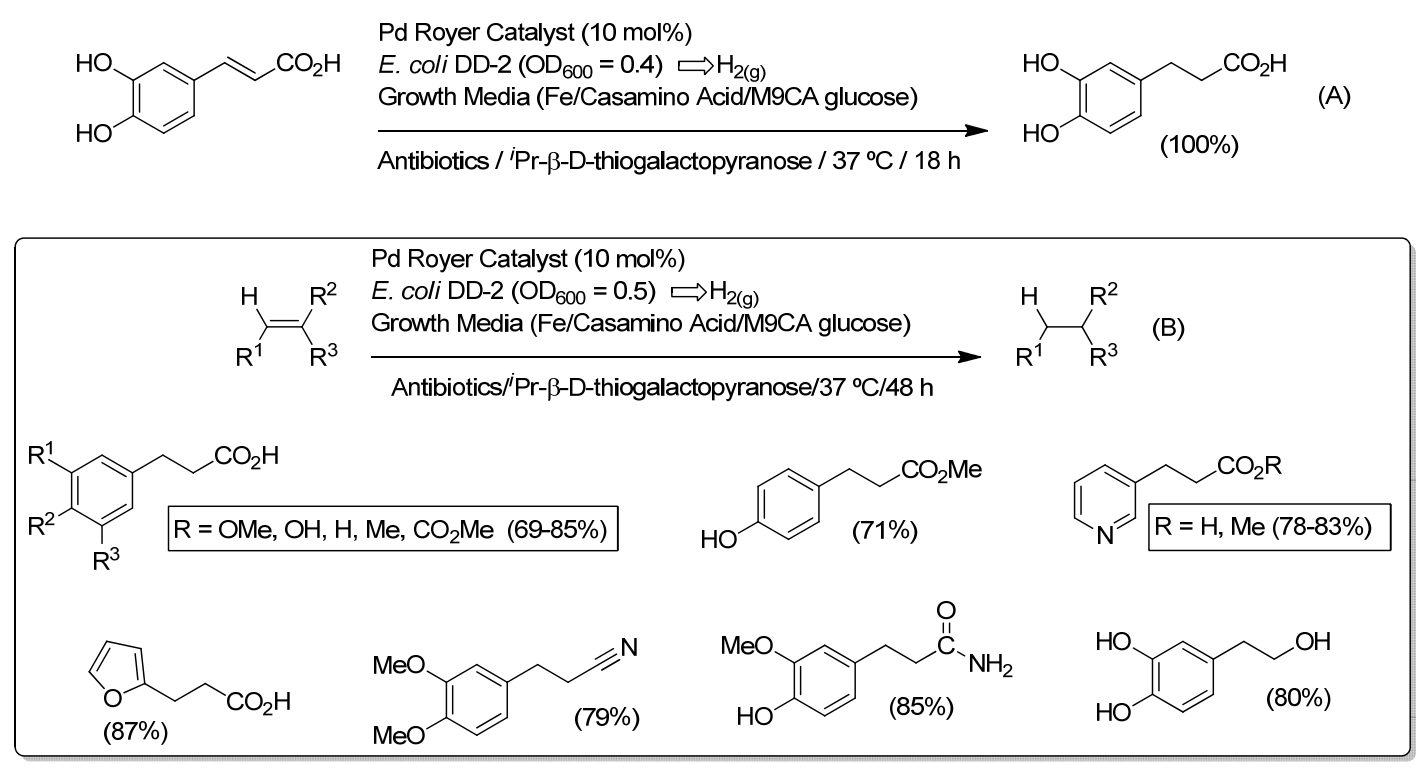

Scheme 10. Hydrogenation of caffeic acid (A) and functionalized olefins (B) in cell grow media (E. coli DD-2) catalyzed by Royer catalyst (Pd-NPs) employing $\mathrm{H}_{2}$ generated in situ by microbial metabolism.

3.3. Combination of Rh-Catalyzed Hydrogenation of Phenol, Double Biooxidations (Alcohol Dehydrogenase/Monooxygenase) and Lipase-Catalyzed Polymerization for the Chemoenzymatic Synthesis of Poly-E-caprolactone

Aromatic rings are usually difficult to saturate due to the concomitant loss of the aromaticity; thus, this hydrogenation reaction is commonly effected with heterogeneous catalysts. In this sense, commercially-available $\mathrm{Rh} / \mathrm{C}$ catalyst is able to hydrogenate a variety of aromatic rings in water under mild reaction conditions [64]. Taking this idea into account, Gröger, Liese and co-workers designed a chemoenzymatic route for the synthesis of poly- $\varepsilon$-caprolactone by utilizing the following sequence of reactions: (i) aqueous $\mathrm{Rh}$-catalyzed hydrogenation of phenol (PhOH) into cyclohexanol; (ii) alcohol dehydrogenase/monooxygenase biocatalyzed double oxidation of $\mathrm{PhOH}$ into $\varepsilon$-caprolactone in water; and (iii) lipase-catalyzed polymerization of $\varepsilon$-caprolactone in an organic solvent [65] (Scheme 11). Metal-catalyzed hydrogenation of phenols in water and under heterogeneous conditions usually gives rise to both cyclohexanone and cyclohexanol as a mixture of products. However, by using the heterogeneous catalyst $\mathrm{Rh}(0)-\mathrm{SBA}-15$ (consisting of Rh-NPs entrapped in mesoporous silica [66]), $\mathrm{PhOH}$ could be converted into the desired cyclohexanol in almost quantitative conversion (99\%), in aqueous media and under mild reaction conditions $\left(75^{\circ} \mathrm{C}\right.$ and 1 bar of $\left.\mathrm{H}_{2}\right)$. This on-water-obtained cyclohexanol was directly double oxidized into $\varepsilon$-caprolactone (without further isolation step) by means of an alcohol dehydrogenase from Lactobacillus kefir (Lk-ADH) and a cyclohexanone monooxygenase from Acinetobacter sp. NCIMB (CHMO), following a previously-described methodology reported by the authors $[67,68]$. At this point, it is worth noting that: (i) both enzymes just required $\mathrm{O}_{2}$ as oxidizing reagent (avoiding co-catalysts); and (ii) the desired $\varepsilon$-caprolactone was obtained in $90 \%$ yield after $24 \mathrm{~h}$ of reaction. In order to avoid the possible inhibition effect of $\varepsilon$-caprolactone on the biocatalyst $\mathrm{CHMO}$, an in situ protocol for the direct extraction of $\varepsilon$-caprolactone from the aqueous reaction media to an organic solvent was assayed by employing a permeable polydimethylsiloxane membrane. Finally, the $\varepsilon$-caprolactone contained in the organic phase (methylcyclohexane) could be utilized as starting

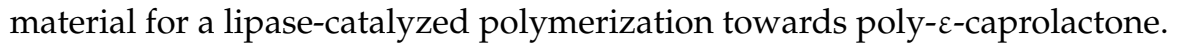




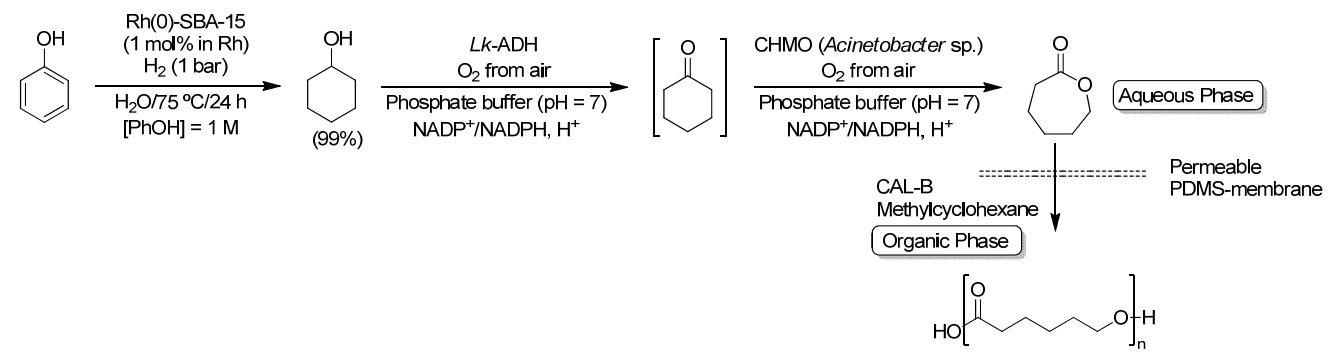

Scheme 11. Chemoenzymatic conversion of phenol into poly- $\varepsilon$-caprolactone by combination of: (i) Rh-catalyzed hydrogenation; (ii) $L k-\mathrm{ADH}$ and cyclohexanone monooxygenase double biooxidation of cyclohexanol; and (iii) lipase-catalyzed polymerization of $\varepsilon$-caprolactone.

\subsection{Combination of Rh-Catalyzed Hydrogenation of Quinolines and Whole Cell-Mediated Asymmetric} Hydroxylation for the Chemoenzymatic Synthesis of 2-Substituted Tetrahydroquinoline-4-ols

Very recently (2017), Chen and co-workers combined the asymmetric transfer hydrogenation (ATH), a process efficiently carried out by transition metal complexes, with a further biohydroxylation performed by whole cells in a sequential procedure (Scheme 12) [69]. Thus, several 2-substitutedquinolines were subjected in a first instance to ATH by the action of a metal complex $(10 \mathrm{~mol} \%)$ prepared in situ from $\left[\mathrm{Cp} \mathrm{RhCl}_{2}\right]_{2}$ and Noyori's ligand $((R, R)-N-(p$-toluenesulfonyl)-1,2diphenylethylenediamine) using sodium formate as the hydrogen source in acetate buffer (pH 5) at $40{ }^{\circ} \mathrm{C}$. After $12 \mathrm{~h}$, the mixture was diluted and incubated at $30^{\circ} \mathrm{C}$ for an extra $24 \mathrm{~h}$ prior to the addition of cells of Rhodococcus equi ZMU-LK19. As a result, the corresponding chiral 2-substituted tetrahydroquinoline-4-ols were obtained in moderate yields (14-47\%) and enabled setting up two stereocenters with excellent diastereo- and enantion-selectivity in some cases ( $d r$ 99:1 and $e e>99 \%$ ).
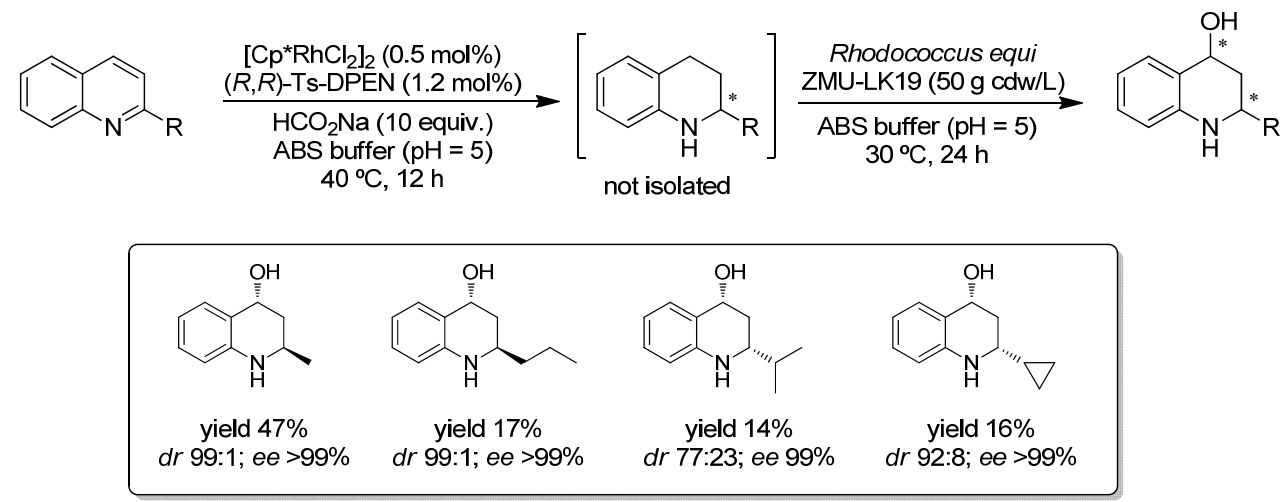

Scheme 12. One-pot/two-step combination of Rh-catalyzed asymmetric transfer hydrogenation and whole cell-mediated asymmetric hydroxylation in aqueous media.

\section{Combination of Metal-Catalyzed Alkene Metathesis in Water with Enzymatic Hydrolyses, Epoxidations, Decarboxylations and Oxidations/Aromatizations}

Metal-catalyzed alkene metathesis is one of the most efficient tools for accomplishing the formation of new C-C bonds [70-72]. In this sense, the development of a plethora of new metal catalyst (usually based in ruthenium) and the optimization of the reaction conditions has led to the establishment of alkene metathesis as a general and reliable methodology in organic synthesis. Several types of metathesis transformations (RCM (ring-closing metathesis) and CM (cross-metathesis), among others) have been carried out in water by: (i) introducing modifications in the catalyst structure; (ii) using co-solvents; or (iii) employing surfactants [73-75]. Thus, in this section, we cover the fruitful combination of two different Ru-catalyzed metathesis protocols (RCM and CM) in aqueous media with several biocatalyzed organic reactions [76-80]. Although none of the discussed protocols permits 
the synthesis of enantiopure products, they constitute very important contributions in the field of chemoenzymatic cascade processes performed in aqueous media and are worth mention in this review.

\subsection{Combination of Ru-Catalyzed Ring-Closing Metathesis of Diallyl Malonates or Anilines with Ester Hydrolysis or Whole Cell-Promoted Oxidation/Aromatization}

At the end of 2011, Gröger, Schatz and co-workers illuminated the way to follow in the combination of Ru-catalyzed metathesis of alkenes and biocatalysis in aqueous media, by reporting the preparation of cyclic malonic acid monoesters in water through the amalgamation of ruthenium-catalyzed RCM of diallyl malonates with the subsequent hydrolysis promoted by pig liver esterase (Scheme 13) [76]. Firstly, the metal-catalyzed ring closing metathesis of the desired diallyl malonate was promoted by Grubbs II catalyst in water [81], either at the analytical (NMR tube) or the preparative scale (5.0-7.0 mL of a $0.5 \mathrm{M}$ solution of diallyl malonate), finding excellent conversions independent of the magnitude of the process (Scheme 13A). Secondly, the enzymatic mono-hydrolysis of the corresponding cyclopentene dicarboxylate was parametrized by employing a pig liver esterase in water. An important finding was that the use of ${ }^{t} \mathrm{BuOH}$ as the co-solvent unlocks the desired mono-hydrolysis (hampering both decarboxylation and transesterification side reactions) and yields the desired cyclic malonic acid monoesters in high yield (92\%) and excellent selectivity (100\%, Scheme 13B). The authors also investigated the compatibility of the Grubbs II catalyst and the enzyme (pig liver esterase) by studying the enzymatic hydrolysis in the presence of the ruthenium complex. Interestingly, almost the same enzymatic activity was observed in the presence or in the absence of Grubbs II catalyst. Accordingly, a one-pot/two-step methodology allowed the direct conversion of diallyl malonates into cyclic monoacid esters in aqueous media (Scheme 13C).
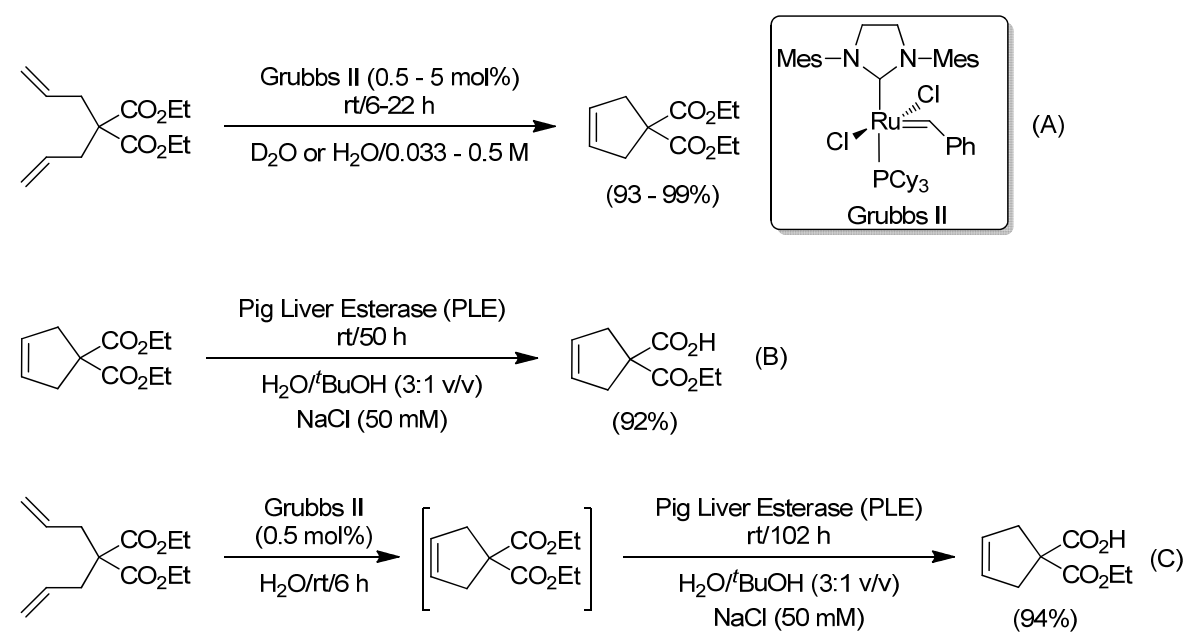

Scheme 13. Ru-catalyzed ring-closing metathesis (RCM) (A), enzymatic ester hydrolysis catalyzed by PLE (B) and one-pot/two-step combination of both in aqueous media (C).

Recently, and following this idea (Ru-catalyzed RCM + enzymatic organic transformations), Turner, Castagnolo and co-workers have reported the combination of the Ru-catalyzed ring-closing metathesis of diallyl anilines (to produce the corresponding 3-pyrrolines) and the subsequent biocatalytic aromatization of the resulting heterocycles (mediated by whole cells containing monoamine oxidases MAO-N variants D5, D9 and D11 [82-84] or the nicotine oxidase biocatalyst 6-HDNO (HDNO = 6-hydroxy-D-nicotine oxidase) [85]) for the synthesis of pyrroles in aqueous media (Scheme 14) [77]. In this case, and in contrast to the aforementioned results reported by Gröger, the authors firstly parametrized the biocatalytic transformation, thus studying the aromatization of different 3-pyrrolines promoted by monoamine oxidases MAO-N or 6-HDNO (Scheme 14A). All the enzymatic studies were carried out at $37^{\circ} \mathrm{C}$, in a buffer solution ( $\left.\mathrm{pH} 7.8\right)$ and using DMF as the 
co-solvent when necessary. The desired pyrroles were obtained in moderate to excellent yields depending on: (i) the substituents on the starting 3-pyrrolines; and (ii) the nature of the monoamine oxidase (the best conversion was obtained when MAO-D5 was used). Once the parametrization study of the biocatalyzed aromatization was accomplished, the authors examined the combination of the Grubbs II-catalyzed RCM of diallyl anilines (Scheme 14B) with the enzymatic aromatization of the in situ-obtained 3-pyrrolines, finding a dramatic effect of the co-solvent employed. Thus, when DMF was utilized, only $10 \%$ of the pyrroline was obtained. This result was attributed to an erosion of the catalytic activity of monoxide aminase (MAO-D5) due to the presence of the ruthenium catalyst in the reaction medium. This unexpected shortcoming was circumvented by the use of a non-water miscible co-solvent (isooctane), which prevents the deactivation of the enzyme (suspended in water) as the ruthenium catalyst remained in the immiscible organic phase. Under these biphasic reaction conditions (Scheme 14C), this chemoenzymatic cascade was extended to a variety of diallyl amines giving rise to the corresponding pyrroles in moderate to good yields.

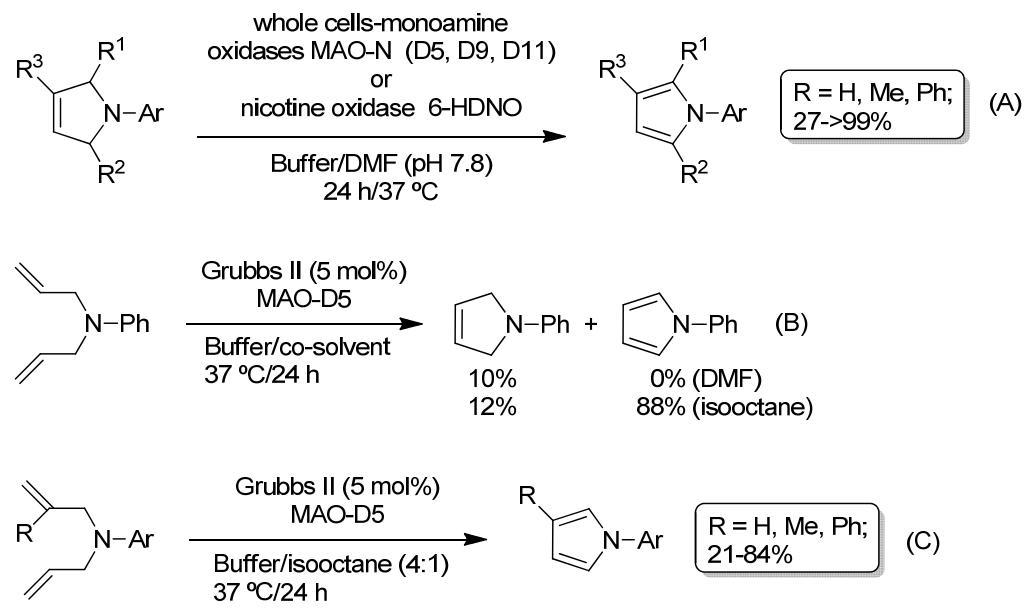

Scheme 14. Enzymatic aromatization (A), Ru-catalyzed ring-closing metathesis (RCM) (B), and chemoenzymatic cascade reaction for the synthesis of pyrroles through their combination in aqueous media (C).

\subsection{Assembly of Ru-Catalyzed Cross-Metathesis (RCM) of Functionalized Olefins with Enzymatic Decarboxylation or P450 Promoted Epoxidation Reactions}

Not only the Ru-catalyzed ring-closing metathesis (RCM) of different diallyl compounds, but also the Ru-catalyzed cross-metathesis (CM) of functionalized olefins has been productively assembled with different biotransformations [78-80]. Thus, the first work in this field was reported by Zhao, Hartwig and co-workers in 2014 by describing the combination of the ruthenium-catalyzed CM between 10-undecenoic acid and trans-3-hexene with the subsequent epoxidation of the in situ-generated 10-tridecenoic acid using P450 BM3 from Bacillus megaterium in a biphasic medium [78]. Prior to this study, the authors assessed that P450 BM3 (combined with a phosphite dehydrogenase regeneration system) reacted with more than five-fold preference for the epoxidation of 10-tridecenoic acid over 10-undecenoic acid. Based on these results, different variants of the Hoveyda-Grubbs II catalysts (several Hoveyda-Grubbs II catalysts have been described as air stable compounds able to operate in protic media $[86,87]$ ) were tested in a biphasic isooctane/aqueous buffer medium containing P450 BM3. Thus, the best results were observed for the ruthenium Complex 7 (Scheme 15), which gives rise to an equilibrium mixture containing the expected cross-metathesis products (cis- and trans-10-tridecenoic acids) and the corresponding self-assembly product. The utilization of this biphasic catalytic system permitted the metathesis reactions to take place in the organic phase, while the biocatalyzed epoxidation occurred in the buffer solution. Further parametrization studies, related to the concentration of the fatty acid and the ratio of trans-3-hexene and 10-undecenoic acid, were needed 
to achieve yields up to $90 \%$ of the final epoxide product after $12 \mathrm{~h}$ of reaction. Finally, the tandem olefin cross-metathesis/epoxidation process was extended to the mixture 4-butenyloxybenzoic acid/trans-3-hexene.

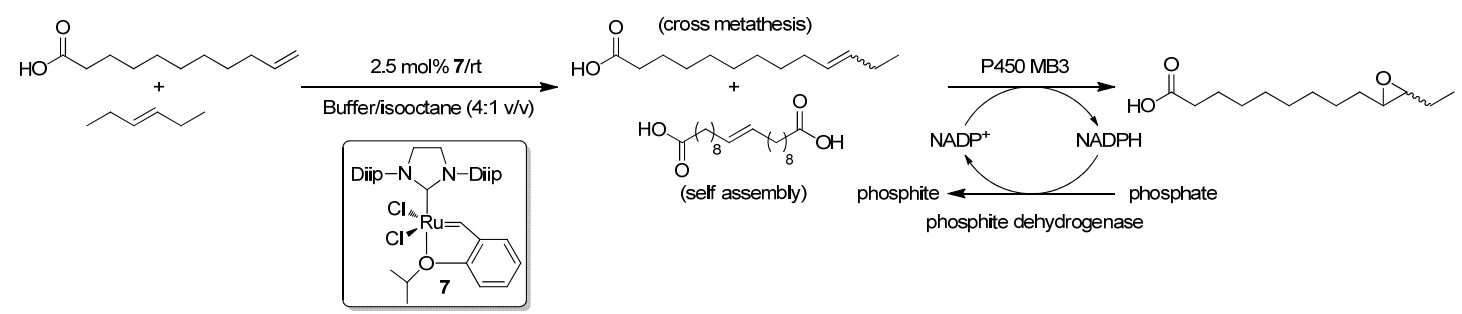

Scheme 15. Chemoenzymatic tandem olefin cross-metathesis/epoxidation of 10-undecenoic acid with trans-3-hexene in a biphasic reaction media catalyzed by Hoveyda-Grubbs II Catalyst 6 and P450 BM3.

More recently, Kourist and co-workers were able to couple the enzymatic decarboxylation of different hydroxycinnamic acids with a ruthenium catalyzed self-assembly metathesis of the in situ-generated functionalized styrenes [79] (Scheme 16). Firstly, the biocatalyzed decarboxylation of several hydroxycinnamic acids promoted by the co-factor-free phenolic acid decarboxylase (bsPAD) was studied in a potassium phosphate buffer (KPi pH 6) at $30{ }^{\circ} \mathrm{C}$ (Scheme 16A). Under these reaction conditions, the corresponding styrenes were obtained in excellent yields (80-95\%). Posteriorly, and as previously observed by Gröger [76] and Castagnolo [77], it was found that the best results for the Ru-catalyzed self-assembly metathesis of the resulting styrenes were obtained when water and air-tolerant Grubbs II (Scheme 13) or Hoveyda-Grubbs II 7 (Scheme 15) catalysts were employed (Scheme 16B). Once the enzymatic decarboxylation and the ruthenium-catalyzed reactions were independently studied, the efforts were focused on the design of a one-pot/one-step reaction. However, the authors observed that: (i) the ruthenium catalysts did not show satisfactory activity under aqueous conditions; and (ii) the catalytic activity of the enzyme was significantly reduced in the presence of an organic solvent. Thus, these drawbacks could be addressed with the following settings: (i) chemoenzymatic reaction was performed in a sequential fashion (one-pot/two-step methodology) in an organic solvent (MTBE, methyl tert-butyl ether); (ii) encapsulation of the decarboxylase in a PVA/PEG cryogel (bsPAD@PVA/PEG) [88]; and (iii) an extra intermediate drying step (employing anhydrous $\mathrm{MgSO}_{4}$ ) before the metathesis reaction (Scheme 16C). Finally, this combination of reactions has been very recently extended by the same authors to $\omega$-hydroxy fatty acids [80].
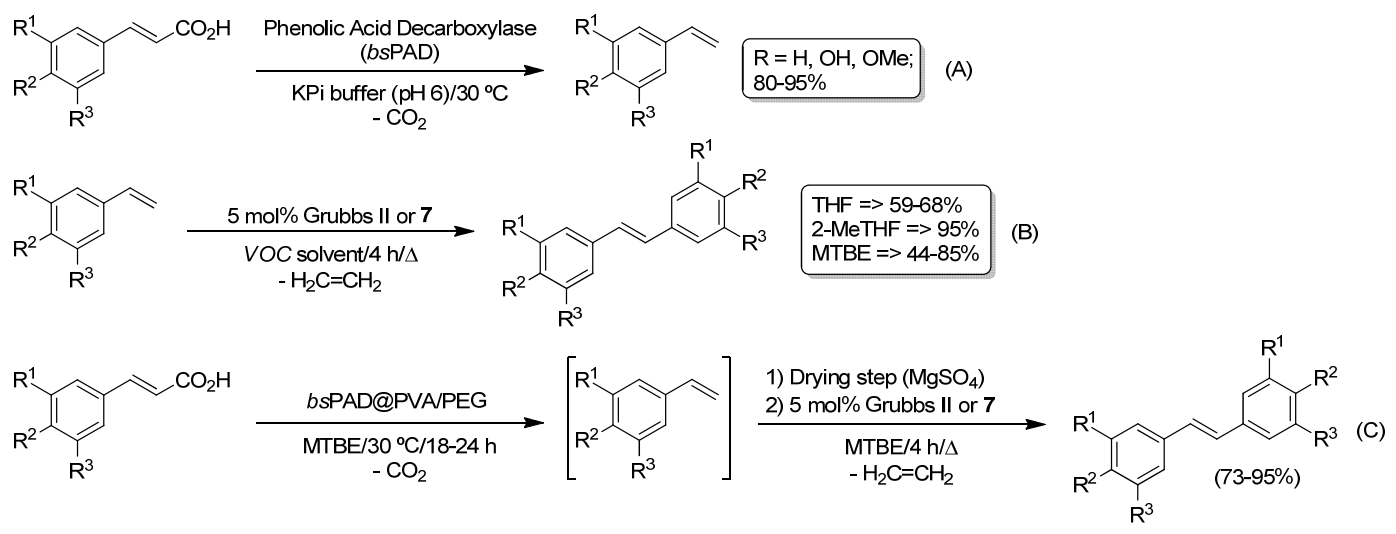

Scheme 16. Decarboxylation of acids by phenolic acid decarboxylase (bsPAD) (A), Ru-catalyzed self-assembly metathesis (B), and chemoenzymatic one-pot/two-step combination of encapsulated phenolic acid decarboxylase (bsPAD) and Ru-catalyzed self-assembly metathesis (C). 


\section{Combination of Copper-Catalyzed Click Chemistry Cycloadditions (CuAAC) with Biocatalytic Ring-Opening Reactions or Bioreductions}

The independent findings by Meldal [89] and Sharpless [90] on the regioselective Copper(I)-catalyzed Azide-Alkyne Cycloadditions (CuAAC) permitted the discovery of a highly-reliable tool for the synthesis of 1,2,3-triazoles under "click chemistry" conditions [91]. This copper-catalyzed cycloaddition reaction presents several attractive features (water tolerability, usually conducted at room temperature and orthogonality) that make this transformation an ideal candidate for the design of metal- and bio-catalyzed tandem transformation in aqueous media. Thus, we review in this section the amalgamation of CuAAC reactions in aqueous media with several biocatalytic transformations, like the epoxide ring-opening [92] or the enantioselective bioreduction of prochiral ketones [93,94].

\subsection{Combination of Biocatalytic Epoxide Ring-Opening (Halohydrin Dehalogenase) with Cu(I)-Catalyzed Cycloaddition of 1,2-Azido Alcohols and Terminal Alkynes in Aqueous Media}

The first reported example of the sequential combination of CuAAC reactions and biotransformations in aqueous media was described by the Nobel Prize laureate Prof. Ben Feringa and co-workers, through studying the one-pot combination of the enantioselective azidolysis of functionalized styrene oxides (performed by halohydrin dehalogenase (HheC) from Agrobacterium radiobacter) with the subsequent $\mathrm{CuAAC}$ reaction with terminal alkynes to produce chiral hydroxyl-triazoles with excellent enantiomeric excess [92]. In this work, the authors started their investigations by studying the catalytic activity of a halohydrin dehalogenase (HheC with cysteine 153 mutated into serine [95]) towards the enantioselective azidolysis of different aromatic epoxides in the presence of a "click" catalytic system containing $\mathrm{CuSO}_{4} \cdot 5 \mathrm{H}_{2} \mathrm{O}$, the required reducing agent (sodium ascorbate, NaAsc) and Feringa's ligand MonoPhos in a potassium phosphate buffer (KPi) (Scheme 17A). Under these conditions, nearly full conversion was achieved for $p$-nitro styrene oxide with $>99 \%$ and $83 \%$ ee for the azido alcohol and the epoxide, respectively. Having proven that the biocatalyzed azidolysis is able to proceed in the presence of the copper catalyst, the one-pot ring opening and subsequent click reaction was attempted with the following findings: (i) the first step sustains its selectivity; and (ii) the click reaction $\left(5 \mathrm{~mol} \%\right.$ of $\left.\mathrm{CuSO}_{4} \cdot 5 \mathrm{H}_{2} \mathrm{O}\right)$ is able to convert all the in situ-generated azido alcohol into the desired triazole. Finally, a Cu-free click chemistry reaction was reported by employing highly-strained alkynes like cyclooctyne.
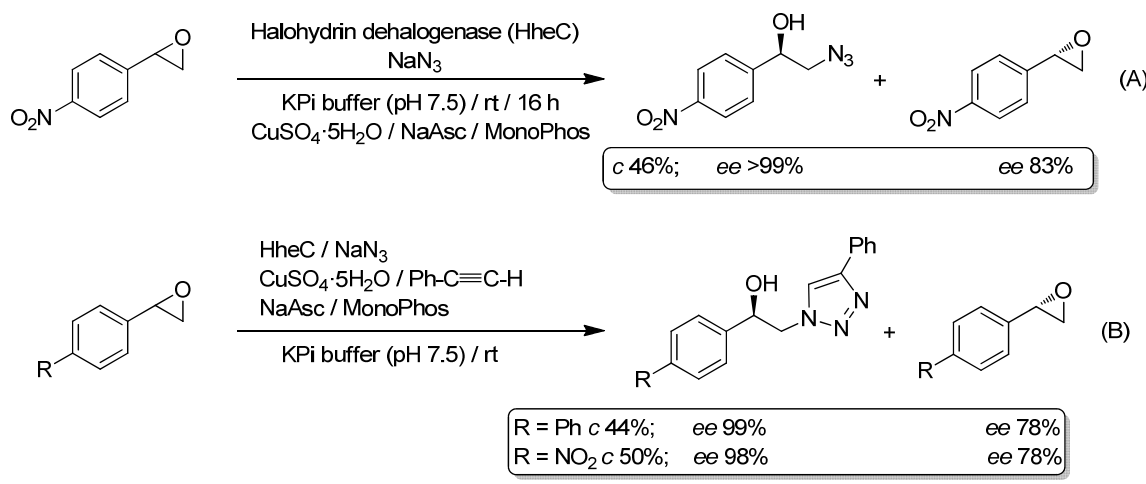

Scheme 17. Azidolysis of styrene oxides (halohydrin dehalogenase, HheC) (A) and its chemoenzymatic one-pot combination with a subsequent $\mathrm{CuAAC}(\mathbf{B})$ in aqueous media.

\subsection{Combination of Whole Cell-Promoted Bioreduction/Azidolysis or ADH Biocatalyzed Reactions with $\mathrm{Cu}(\mathrm{I})$-Catalyzed Cycloaddition in Aqueous Media}

After the previously-mentioned work from Feringa's group [92], the same authors decided to go one step forward by combining whole cell-catalyzed tandem conversion of $\beta$-halo ketones 
into enantiopure $\beta$-azido alcohols and subsequent $\mathrm{CuAAC}$ reaction with $\mathrm{PhC} \equiv \mathrm{CH}$ [93]. In the first step of this sequence, prochiral $\beta$-halo ketones were transformed directly into enantiopure $\beta$-azido alcohols by employing engineered cells that overexpress the two enzymes used in this cascade biotransformation: (i) alcohol dehydrogenases (AdhT (an $R$-selective alcohol dehydrogenase from Thermoanaerobacter sp.); or AdhL (an S-selective alcohol dehydrogenase from Lactobacillus brevis)); and (ii) halohydrin dehalogenases (HheC (an $R$-selective halohydrin dehalogenase from Agrobacterium radiobacter) or halohydrin dehalogenase from Mycobacterium $\mathrm{sp}$.)). This tandem procedure was carried out: (i) in a biphasic reaction media based on a mixture of HEPES buffer (0.1 M pH 7.5, $\mathrm{KOH}, 1 \mathrm{mM} \mathrm{MgSO} 4,1 \mathrm{mM} \mathrm{ZnSO} 4$ ) and octane; (ii) at room temperature; and (iii) employing isopropanol for regeneration of the NADPH co-factor. Overnight incubation of the reactions under the aforementioned conditions permitted the synthesis of the desired $\beta$-azido alcohols in full conversion (isolated yield 35-70\%) and enantioselectivities ranging from 96-99\% ee (Scheme 18A). Finally, and in view of the previous positive combination of halohydrin dehalogenase and CuAAC reactions [92], the authors designed a new chemoenzymatic route for the direct conversion of $\beta$-halo ketones into the above-mentioned enantioenriched $\beta$-hydroxy triazoles (Scheme 18B). In the parametrization studies of this chemoenzymatic transformation, the addition of octane as an organic solvent resulted in a reduction of the click reactivity (probably due to extraction of the $\mathrm{PhC} \equiv \mathrm{CH}$ into the organic phase). This unexpected drawback could be evaded just by avoiding this co-solvent.

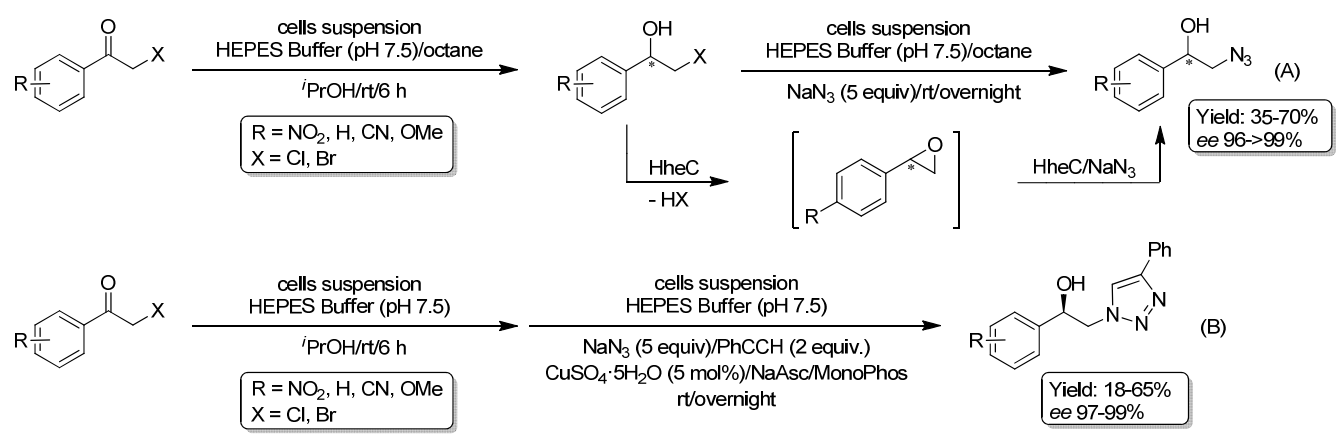

Scheme 18. Whole Cell-Promoted Bioreduction/Azidolysis of $\beta$-halo ketones (A) and its one-pot combination with $\mathrm{CuAAC}$ reaction for the enantioenriched synthesis of $\beta$-hydroxy triazoles in aqueous media (B).

More recently, Gotor and co-workers described a fully-convergent one-pot/two-step procedure for the synthesis of enantioenriched 1,2,3-triazole-derived diols by combining a single alcohol dehydrogenase (ADH) with a CuAAC catalytic system [94]. Thus, two different prochiral compounds, namely an $\alpha$-azido- and an alkynyl-ketone, were converted into the corresponding chiral alcohols by employing different alcohol dehydrogenases (ADH-A from Rhodococcus ruber; ADH-T from Thermoanaerobium sp.; and Tes-ADH from Thermoanaerobacter ethanolicus or commercially-available $\mathrm{Lb}$-ADH from Lactobacillus brevis/Lk-ADH from Lactobacillus kefir) in a reaction mixture containing a phosphate buffer solution ( $\mathrm{pH} 7.5$ ) and ${ }^{\mathrm{i}} \mathrm{PrOH}$ at $30^{\circ} \mathrm{C}$ (Scheme 19). Under these conditions ADH-A and $\mathrm{Lb}$-ADH gave rise to the corresponding chiral alcohols in quantitative conversion and excellent enantiomeric excess. The subsequent click reaction between the in situ-obtained chiral propargylic alcohols and the corresponding chiral azido-alcohols took place at $60^{\circ} \mathrm{C}$ by employing a copper wire with a catalytic amount of $\mathrm{CuSO}_{4}$ allowing obtaining the required $\mathrm{Cu}$ (I)-catalyst via a $\mathrm{Cu}(0) / \mathrm{Cu}(\mathrm{II})$ comproportionation reaction (Scheme 19). This one-pot/two-step chemoenzymatic methodology furnished the desired enantiopure 1,2,3-triazole-derived diols after $24 \mathrm{~h}$ of reaction. 


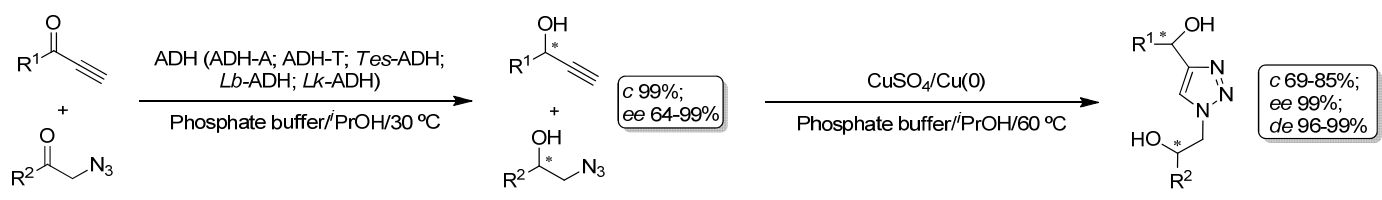

$\mathrm{R}^{1}=\mathrm{Me},{ }^{n} \mathrm{Bu} ; \mathrm{R}^{2}=\mathrm{Ph}, 2-\mathrm{Np},\left(\mathrm{CH}_{2}\right)_{5} \mathrm{CH}_{3}, p-\mathrm{NO}_{2}-\mathrm{Ph}, p-\mathrm{NO}_{2}-\mathrm{OH}$

Scheme 19. Chemoenzymatic one-pot/two-step protocol for the synthesis of chiral 1,2,3-triazole-derived diols in aqueous media.

\section{Combination of Metal-Catalyzed C-C Coupling Reactions with Enzymatic Reductions, Aminations or Halogenations}

Metal-catalyzed C-C coupling reactions constitute nowadays a staple of modern organic chemistry [96-98], as demonstrated by the Nobel Prize award in chemistry to Heck, Negishi and Suzuki in 2010. These C-C coupling reactions are usually promoted by palladium catalysts and form one of the most robust and versatile synthetic tools to achieve the selective and fruitful coupling or organic electrophiles (usually an organic halide or triflate) with a $\mathrm{sp}^{-}-\mathrm{sp}^{2-}$ - or $\mathrm{sp}^{3}$-hybridised carbon. Moreover, water has been extensively used as a reaction medium for these metal-catalyzed C-C coupling reactions [99]. Thus, it is not surprising to find in the literature several examples that reported the combination of metal-catalyzed C-C coupling reactions in aqueous media with different biotransformations. In this sense, this section covers the combination of: (i) Pd-catalyzed Suzuki coupling with bioreductions [100], bioaminations [101] or enzymatic halogenations [102,103]; and (ii) Pd-catalyzed Heck reaction and bioreduction [104]. Furthermore, and in the final part of this section, we review the combination of indium-mediated Barbier-type coupling [105] or Zn-catalyzed aldol reactions [106] with enzymatic oxidations or bioreductions, respectively.

6.1. Combination of Pd-Catalyzed Suzuki Coupling with Bioreductions (ADH), Bioamination (Phenylalanine Ammonia Lyases/D-Amino Acid Dehydrogenase) or Enzymatic Halogenation (Halogenase) in Aqueous Media

Pd-catalyzed Suzuki cross-coupling of aryl, vinyl or alkyl halides (or pseudohalides) with organoboron reagents is one of the most efficient and selective methodologies for the construction of C-C bonds $[97,107,108]$. Importantly for the design of tandem chemoenzymatic procedures, there are several key points that make this metal-catalyzed cross-coupling reaction the ideal partner for biocatalyzed reactions: (i) it usually takes place under mild reaction conditions; (ii) the boron reagents (boronic acids or boronic esters) are generally stable in water, non-toxic and commercially available [109]; and (iii) it tolerates a wide variety of functional groups. The pioneering study in this field was reported in 2008 by Gröger and co-workers through the combination of the Pd-catalyzed Suzuki cross-coupling of $p$-bromo-acetophenone and phenyl boronic acid $\left[\mathrm{PhB}(\mathrm{OH})_{2}\right]$ in aqueous medium with the subsequent bioreduction ( $\mathrm{ADH}$ from Rhodococcus sp.) of the obtained biaryl ketones in a phosphate buffer $(\mathrm{pH} 7)$ and using ${ }^{i} \mathrm{PrOH}$ as co-factor regenerator [100]. Although both reactions proceeded efficiently (conversions greater than $93 \%$ and enantiomeric excess $>99 \%$ ) when carried out separately (Scheme 20A), an unexpected incompatibility of the metal catalytic system $\left[\mathrm{Pd}\left(\mathrm{PPh}_{3}\right)_{2} \mathrm{Cl}_{2}\right] / \mathrm{PPh}_{3} / \mathrm{PhB}(\mathrm{OH})_{2}$ and the enzyme was observed. After several competitive experiments, it was found that while the metal catalyst only had a minor impact on the enzyme, the phosphine $\left(\mathrm{PPh}_{3}\right)$ and the boronic acid $\mathrm{PhB}(\mathrm{OH})_{2}$ had a stronger negative impact on the enzyme activity. By performing these parametrization experiments, the best reaction conditions for a successful sequential process implied: (i) the use of water as solvent; (ii) avoiding the use of the phosphine ligand; and (iii) the employment of a stoichiometric amount of the boronic acid (which should also be entirely consumed in the coupling process). Accordingly, the first step progresses effectively in aqueous media giving rise to the expected biaryl ketone in good yield (95\%). Next, the subsequent bioreduction (promoted by (S)-ADH from Rhodococcus sp.) produced the desired chiral biaryl-substituted alcohol with good conversion (91\%) and excellent enantioselectivity (>99\%). 


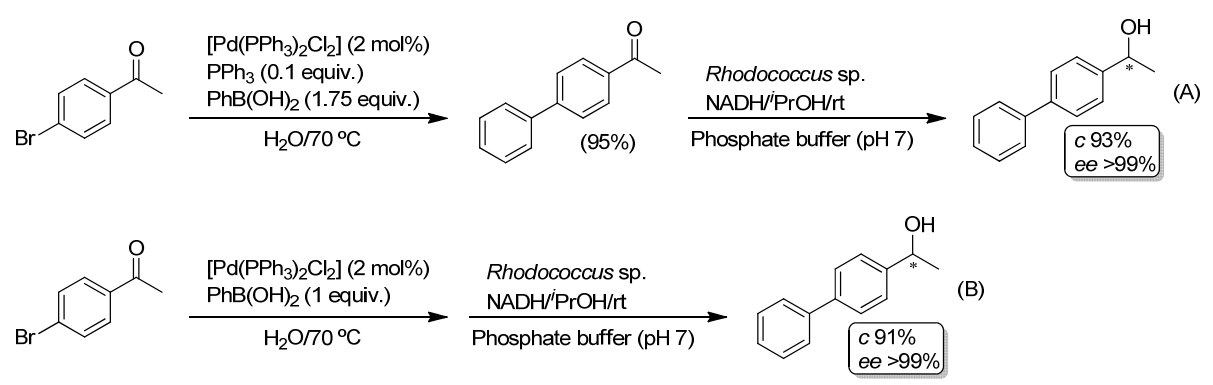

Scheme 20. Chemoenzymatic one-pot/two-step (A) or sequential (B) synthesis of chiral biarylsubstituted alcohols in aqueous media.

Later, and following the aforementioned pioneer work of Gröger and co-workers, Turner et al. reported the successful assembly of the Pd-catalyzed Suzuki C-C coupling reaction with two different enzymatic transformations [101]: (i) the asymmetric hydroamination of arylpropenoic acids, catalyzed by phenylalanine ammonia lyases (PALs) [110]; or (ii) the reductive amination of $\alpha$-keto acids promoted by an NADPH-dependent D-amino acid dehydrogenase (DAADH), engineered from a meso-diaminopimelate dehydrogenase from Corynebacterium glutamicum [111]. Firstly, the authors studied the biotransformation of 4-bromocinnamic acid into L-4-bromophenylalanine promoted by different PALs in a $5 \mathrm{M}$ aqueous ammonia solution $\left(\mathrm{NH}_{4} \mathrm{OH}\right.$, pH 9.6) at $37^{\circ} \mathrm{C}$ for $24 \mathrm{~h}$, obtaining the best results ( $80 \%$ of conversion, $>99 \%$ ee) with a wild-type PAL overproduced in Escherichia coli whole cells from Anabaena variabilis (AvPAL-F107A). The corresponding antipode (D-4-bromophenylalanine, $99 \%$ conversion, $>99 \%$ ee) was easily accessed by promoting a DAADH-catalyzed reductive amination of 4-bromophenylpyruvic acid employing NADPH as co-factor and the glucose/glucose dehydrogenase (GDH) recycling system for its regeneration. Secondly, an additional Boc-protection step of the primary amino group in either L- or D-4-bromophenylalanine was mandatory to achieve quantitative yields of the desired biarylalanine derivatives. Finally, and after this Boc-protection step, it was possible to perform the desired Pd-catalyzed Suzuki reaction by employing the complex $\left[\mathrm{Pd}\left(\mathrm{CH}_{3} \mathrm{CN}\right)_{2} \mathrm{Cl}_{2}\right]$ as the catalyst $(10 \mathrm{~mol} \%)$ with the aid of microwave irradiation at $120^{\circ} \mathrm{C}$ for $20 \mathrm{~min}$ (Scheme 21).

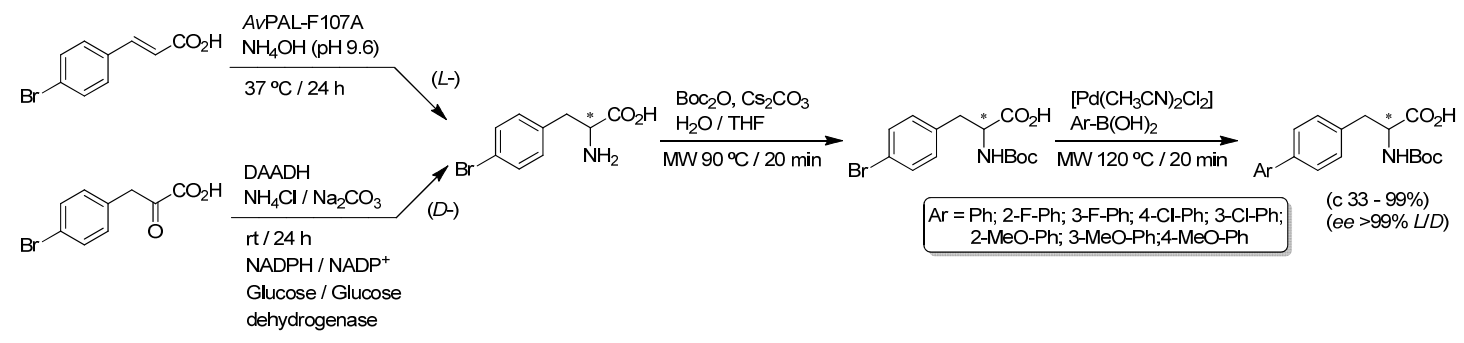

Scheme 21. Chemoenzymatic sequential synthesis of L- or D-biarylalanine derivatives in aqueous media.

Finally, not only bioreductions [100] or bioaminations [101], but also enzymatic halogenations $[102,103]$ have been efficiently coupled with Pd-catalyzed Suzuki reactions. In this sense, Sewald and co-workers [102] were the first to report the combination of the biocatalyzed halogenation of L-tryptophan with the subsequent Pd-catalyzed Suzuki cross-coupling reaction for the chemoenzymatic synthesis of different aryl-substituted tryptophans (Scheme 22). Thus, firstly, the regioselective bromination in the 5-, 6- or 7-position of the indole molecule of tryptophan was studied by employing Trp 5-halogenase PyrH, Trp 6-halogenase Thal or Trp 7-halogenase Rebh [112], respectively. For this biotransformation, the so-called "combiCLEAs methodology" (combiCLEAS $=$ Cross-Linked Enzyme Aggregate) was followed, which selectively brominates L-tryptophan with 
full conversion in the aforementioned positions. This combiCLEAs methodology consists of the precipitation and the cross-linking of the Trp halogenases in the presence of all auxiliary enzymes necessary for concomitant co-factor regeneration [112]. In a second step, the cross-coupling reaction was conducted under Ar atmosphere with different aromatic boronic acids, employing in this case a palladium(II) salt $\left(\mathrm{Na}_{2} \mathrm{PdCl}_{4}\right)$ as the catalyst in the presence of: (i) the water-soluble Buchwald sulfonated phosphine ligand sSPhos; (ii) water as the solvent at $95{ }^{\circ} \mathrm{C}$; and (iii) $\mathrm{K}_{3} \mathrm{PO}_{4}$ as the base. Lastly, the extraction of the final zwitterionic products from the aqueous media could be facilitated just by protecting the primary amino group with $\mathrm{Boc}_{2} \mathrm{O}$ (Scheme 22). In the same year (2016), Latham, Henry and co-workers designed a closely-related and integrated catalytic system for the regioselective biocatalytic bromination of a range of aromatic scaffolds (anthranilamide, tryptophol, 3-indole propionate or 6-hydroxy isoquinoline) and subsequent Pd-catalyzed Suzuki coupling reaction. The observed issues of enzyme and transition metal $(\mathrm{Pd})$ compatibility were overcome through membrane compartmentalization of the different catalytic systems [103].

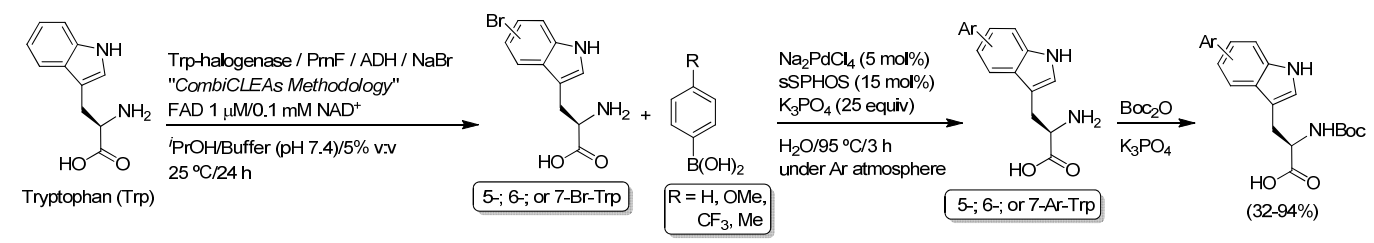

Scheme 22. Chemoenzymatic modular combination of enzymatic bromination of tryptophan (Trp) with the Pd-catalyzed Suzuki reaction in aqueous media.

\subsection{Combination of Pd-Catalyzed Heck Reaction of Aryl Iodides and Allylic Alcohols with a Subsequent Bioreduction (Lb-ADH from Lactobacillus brevis) in Aqueous Media}

The catalytic Heck coupling reaction (also called Mizoroki-Heck coupling after the pioneering and independent reports of T. Mizoroki [113] and R.F. Heck [114]) is an essential catalytic tool in organic synthesis as it allows the selective and efficient formation of new C-C bonds between two $\mathrm{sp}^{2}$-hybridized carbon atoms (activated alkenes and aryl/vinyl halides). In this sense, palladium-nanoparticles (Pd-NPs) have been extensively employed as catalyst for the Heck reaction, since the pioneering work from Beller [115]. The major advantages related to the employment of metal nanoparticles in the Heck reaction include [116]: (i) high catalytic activity; (ii) excellent selectivity; and (iii) tolerance of water [117,118]. Bearing in mind these benefits of Pd-NP-catalyzed Heck reaction in water, Cacchi and co-workers reported a one-pot/two-step process connecting the aqueous Heck reaction with an enantioselective $\mathrm{ADH}$-catalyzed bioreduction of the transiently-formed prochiral hydroxyl-ketone to produce the chiral alcohol (R)-(-)-rhododendrol (Scheme 23) [104]. In the first step, the Heck reaction of aryl iodides and allylic alcohols was performed under standard bench experimental conditions (aqueous media, under air and in the presence of $\mathrm{NaHCO}_{3} / \mathrm{NaOH}$ as the base) at $100{ }^{\circ} \mathrm{C}$ promoted by a phosphine-free perfluoro-tagged Pd-NPs immobilized on fluorous silica gel (Pd-NP-FSG) (two different kinds of Pd-NPs immobilized on fluorous silica gel (through F-F interactions or covalent bonding) have been employed by the authors). After cooling down the reaction, $\mathrm{ADH}$ from Lactobacillus brevis ( $\mathrm{Lb}-\mathrm{ADH}), \mathrm{NADPH}$ and ${ }^{\mathrm{i}} \mathrm{PrOH}$ were added to the reaction crude and the obtained mixture stirred at room temperature for $24 \mathrm{~h}$, yielding the desired $(R)-(-)$-rhododendrol (Scheme 23) in good isolated yield (90\%) and excellent enantiomeric excess (>99\%). 


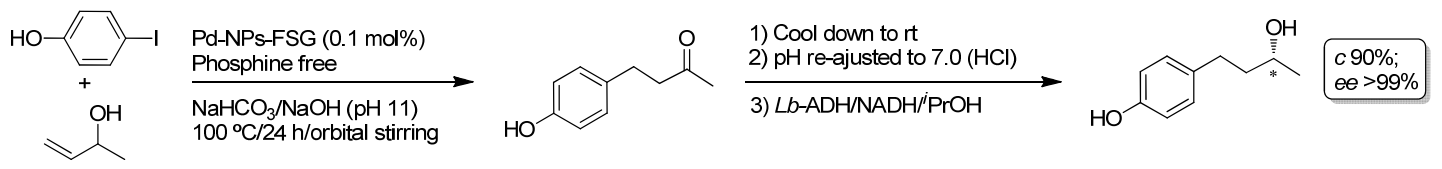

Scheme 23. Chemoenzymatic synthesis of $(R)-(-)$-rhododendrol through the combination of the Pd-catalyzed Heck reaction and ADH-catalyzed enantioselective bioreduction of a prochiral ketone in aqueous media. FSG, fluorous silica gel.

6.3. Combination of Indium-Mediated Barbier-Type Coupling and Zn-Catalyzed aldol Reaction with Enzymatic Oxidations (Galactose Oxidase) or Bioreductions (Oxidoreductases), Respectively

The metal-mediated (Mg, Al, Zn, In, Sn or their salts) Barbier reaction [119], which involves the reaction between a carbonyl compound and an organic halide or pseudohalide [120], is an important methodology for producing new C-C bonds and has been extensively developed in non-conventional solvents (like water) [121]. In addition, it is important to note that the allylation of aldehydes under Barbier conditions typically takes place faster and produces the desired alcohols in higher yields when water is used as the solvent [122]. Accordingly, Faber, Kroutil and co-workers explored the chemoenzymatic one-pot/two-step transformation of benzyl or cinnamic alcohols to the corresponding homoallylic alcohols in water through the combination of: (i) the enzymatic alcohol oxidation to produce the corresponding aldehydes (promoted by galactose oxidase); with (ii) the indium(0)-mediated Barbier type reaction with allyl bromide (Scheme 24) [105]. Firstly, the aqueous oxidation of benzyl alcohol promoted by galactose oxidase from Fusarium NRRL2903 in the presence of horseradish peroxidase (HRP) and 2,2'-azino-bis(3-ethylbenzothiazoline-6-sulfonic acid) (ABTS) was parametrized for the removal of hydrogen peroxide under atmospheric air (4 bar) and with $\mathrm{CuSO}_{4}(10 \mathrm{mM})$ as the co-catalyst. Under these conditions, the desired benzaldehyde was obtained in quantitative yield (>99\%). Unfortunately, this enzymatic oxidation was completely inhibited in the presence of the reagents required for the second reaction (the $\operatorname{In}(0)$-promoted allylation). However, this undesired circumstance was circumvented by performing the reaction in a sequential fashion. Thus, the allylation reaction proceeded smoothly even in the presence of the enzymatic catalytic system, giving rise to the desired homoallylic alcohols in good yields (51->99\%).

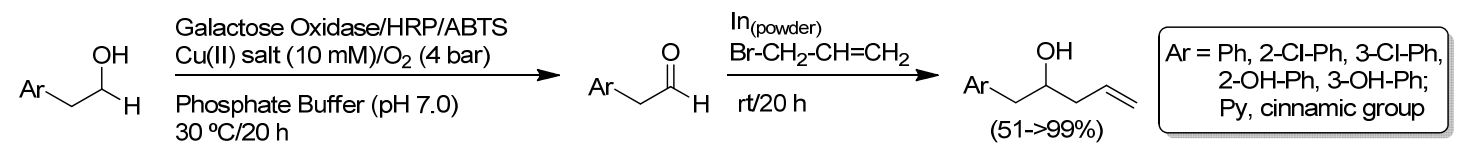

Scheme 24. Enzymatic alcohol oxidation/In-mediated Barbier coupling cascade reaction in aqueous media.

To finish this section, we would like to point out that Aoki and co-workers [106] have reported the combination of an enantioselective $\mathrm{Zn}$-catalyzed aldol reaction (between different aromatic aldehydes and acetone) with the subsequent enantioselective bioreduction of the aldol products promoted by commercially-available NADH-dependent oxidoreductases (i.e., from baker's yeast, S. cerevisiae, L. kefir or Daicel Co. Ltd., Tokyo, Japan) employing a phosphate buffer (pH 7.2) as reaction media. All four possible stereoisomers of the obtained optically-active 1,3-diols could be selectively produced by employing this chemoenzymatic methodology.

\section{Combination of Metal-Catalyzed Oxidations with Enzymatic Reductions}

Metal-catalyzed selective oxidation of alcohols is widely recognized as a particularly useful methodology in the production of aldehydes or ketones [123], which are very important building blocks in the production of flavors, fragrances or biologically-active compounds, among others. However, the vast majority of these protocols are incompatible with biotransformations, as they usually require 
the use of: (i) highly reactive chemicals (chromium salts, oxalyl chloride or hypervalent iodines); (ii) volatile organic solvents (toluene) or solvent-free conditions; and (iii) strong bases (i.e., $\mathrm{NaOH}$, $\mathrm{KO}^{t} \mathrm{Bu}$ ) as co-catalysts. Nevertheless, Kroutil and co-workers were able to design an iridium-catalyzed oxidation of secondary alcohols in an aqueous/toluene reaction mixture via hydrogen transfer by employing a sterically-hindered ketone as the hydrogen acceptor (Scheme 25A) [124]. The selection of the suitable hydrogen acceptor was crucial to minimize its possible cross-bioreduction with ADH-A. However, and even under the best catalytic conditions (10 equiv. of the acceptor and $5 \mathrm{~mol} \%$ of iridium catalyst), only $67 \%$ conversion could be reached.

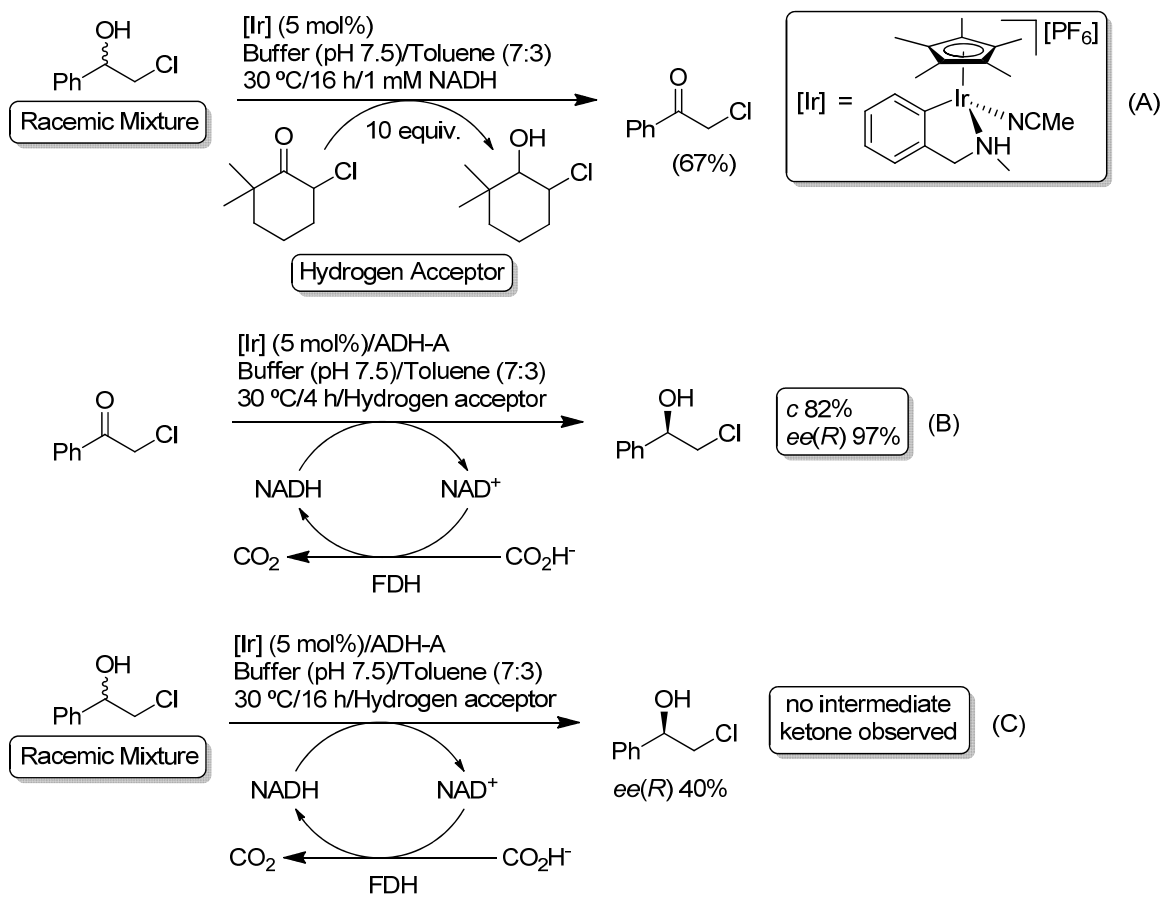

Scheme 25. Ir-catalyzed oxidation of halohydrins (A), bioreduction of -halo ketones (B) and their combination in aqueous media (C).

Posteriorly, the authors studied the compatibility of the iridium catalyst and the ADH-A from Rhodococcus ruber by carrying out the bioreduction of the desired chloroketone in the presence of both catalysts (metal and enzyme) employing formate dehydrogenase/formate (FDH/formate) as a recycling system for the co-factor NADH (Scheme 25B). Satisfactorily, after $4 \mathrm{~h}$ of reaction, the alcohol was produced in $82 \%$ conversion and $97 \%$ enantiomeric excess, thus proving that the biocatalytic system $\mathrm{ADH}-\mathrm{A} / \mathrm{NADH} / \mathrm{FDH} /$ formate was active even in the presence of the iridium catalyst. Finally, the iridium-catalyzed oxidation and the bioreduction were connected in a concurrent process (Scheme 25C), allowing the conversion of the starting racemate into the enantioenriched alcohol with a $40 \% e e$ and in the absence of the intermediate ketone (the obtained $e e$ is lower than $97 \%$ thus showing that the metal catalyst can perform an undesired racemization of the final $(R)$-enantiomer of the alcohol in the presence of the biocatalytic sytem [125]).

More recently (2015), Gröger and co-workers reported the combination of the Pd/Cu-catalyzed Wacker oxidation of olefins with the concomitant bioreduction of the transiently-formed ketones in a one-pot process in aqueous media (Scheme 26) [126]. The initial studies showed that the presence of the copper and palladium salts in the reaction media eroded dramatically the activity of the alcohol dehydrogenase from Lactobacillus kefir ( $L k-\mathrm{ADH})$. To overcome this drawback, an ingenious strategy based on the compartmentalization of the two different catalytic systems (metals and enzyme) was designed by employing a polydimethylsiloxane (PDMS) thimble [127]. The hydrophobic properties of this membrane allow the in situ-formed ketone to selective flux through the membrane 
while the metallic salts remained in the interior of the thimble. Moreover, the biocatalytic system $\left(\mathrm{Lk}-\mathrm{ADH} / \mathrm{NADP}^{+}\right)$remains in the exterior of the thimble, thus preventing the erosion of the biocatalyst by the metal salt. However, under these one-pot/one-step conditions, the Wacker oxidation inside the thimble only produced the desired ketone in a $20 \%$ yield. This unexpected limitation is related to the flux to the exterior of the membrane of the co-solvent $(\mathrm{MeOH})$ employed in the Wacker oxidation. To suppress this leaching of methanol, the Wacker oxidation and the enzymatic reduction were conducted in a sequential fashion (the biocatalytic system was added to the exterior of the thimble once the oxidation was finished in the interior). As a result, it was possible to convert several aromatic alkenes into the corresponding 1-arylethanols with high conversion $(>95 \%)$ and excellent enantiomeric excess (98-99\%).

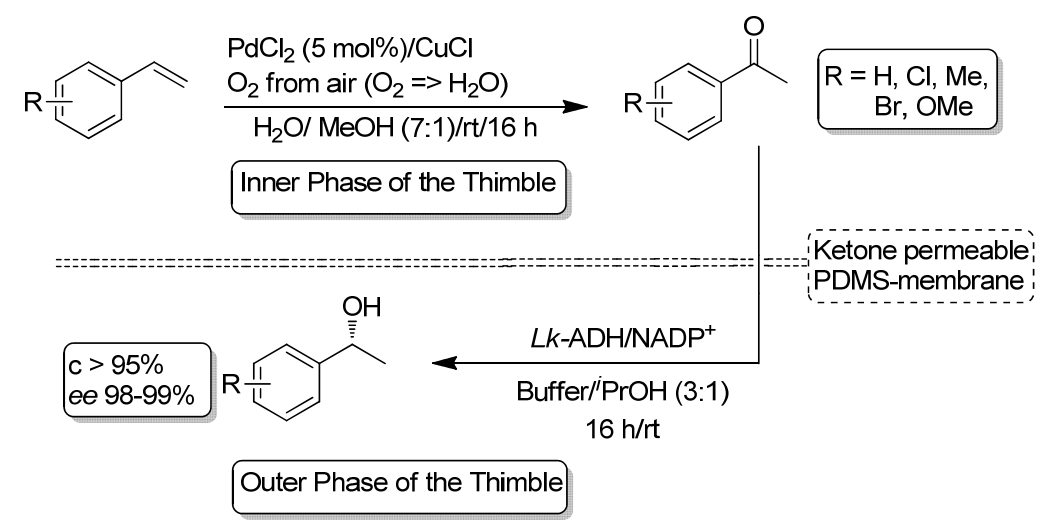

Scheme 26. Compartmentalization strategy for Pd/Cu-catalyzed Wacker oxidation of olefins and ADH-mediated bioreduction of aromatic ketones by employing a polydimethylsiloxane (PDMS) thimble in aqueous media.

\section{Conclusions}

This review presents a summary of the recent findings in the development of new catalytic networks that combine both metallic and biological catalysts in aqueous media for the synthesis of enantiopure organic molecules. Although the assembly of these different catalytic worlds implies important challenges like (i) metal- and bio-catalyst compatibility and stability, (ii) undesired cross-reactivity and (iii) the employment of different catalytic reaction conditions, we have shown a series of ingenious and straightforward chemoenzymatic processes able to produce highly-added-value enantioenriched organic products under mild reaction conditions. Among others, the combination of metal-catalyzed isomerizations, cycloadditions, hydrations, olefin metathesis, oxidations, C-C cross-coupling and hydrogenation reactions, with several biotransformations (enzymatic reduction, amination, epoxidation, halogenation or ester hydrolysis) have been covered.

Now that the first seeds have been planted and bearing in mind the almost infinite possible combinations of metal- and bio-catalyzed organic reactions, we strongly believe that this chemoenzymatic methodology will play a more prominent role within the toolbox of synthetic organic chemists in the near future, with new and astonishing breakthroughs to be discovered.

Acknowledgments: We are indebted to the MINECO of Spain (CTQ2016-81797-REDC and CTQ2016-75986-P) and the Gobierno del Principado de Asturias (Project GRUPIN14-006) for financial support. Joaquín García-Álvarez thanks the Fundación BBVA for the award of a "Beca Leonardo a Investigadores y Creadores Culturales 2017".

Conflicts of Interest: The authors declare no conflict of interest. The founding sponsors had no role in the design of the study; in the collection, analyses, or interpretation of data; in the writing of the manuscript, and in the decision to publish the results. 


\section{References}

1. Dach, R.; Song, J.J.; Roschangar, F.; Samstag, W.; Senanayake, C.H. The Eight Criteria Defining a Good Chemical Manufacturing Process. Org. Process Res. Dev. 2012, 16, 1697-1706. [CrossRef]

2. Lam, F.L.-Y.; Li, M.C.L.; Chau, R.S.L.; Arancon, R.A.D.; Hu, X.; Luque, R. Catalysis at room temperature: Perspectives for future green chemical processes. Wiley Interdiscip. Rev. Energy Environ. 2015, 4, 316-338. [CrossRef]

3. Rothenberg, G. Catalysis: Concepts and Green Applications; Wiley-VCH Verlag GmbH \& Co. KGaA: Weinheim, Germany, 2008.

4. Anastas, P.T. (Ed.) Hanbook of Green Chemistry, Vols. 4, 5 and 6, Green Solvents; Wiley-VCH: Weinheim, Germany, 2010.

5. Laird, T. Green chemistry is good process chemistry. Org. Process Res. Dev. 2012, 16, 1-2. [CrossRef]

6. Sheldon, R.A.; Pererira, P.C. Biocatalysis engineering: The big picture. Chem. Soc. Rev. 2017, 46, $2678-2691$. [CrossRef] [PubMed]

7. López-Gallego, F.; Schmidt-Dannert, C. Multi-enzymatic synthesis. Curr. Opin. Chem. Biol. 2010, 14, $174-183$. [CrossRef] [PubMed]

8. Ricca, E.; Brucher, B.; Schrittwieser, J.H. Multienzymatic Cascade Reactions: Overview and Perspectives. Adv. Synth. Catal. 2011, 353, 2239-2262. [CrossRef]

9. Xue, R.; Woodley, J.M. Process technology for multi-enzymatic reaction systems. Bioresour. Technol. 2012, 115, 183-195. [CrossRef] [PubMed]

10. García-Junceda, E.; Lavandera, I.; Rother, D.; Schrittwieser, J.H. (Chemo)enzymatic cascades-Nature's synthetic strategy transferred to the laboratory. J. Mol. Catal. B Enzym. 2015, 114, 1-6. [CrossRef]

11. Hayashi, Y. Pot economy and one-pot synthesis. Chem. Sci. 2016, 7, 866-880. [CrossRef] [PubMed]

12. Hönig, M.; Sondermann, P.; Turner, N.J.; Carreira, E.M. Enantioselective Chemo- and Biocatalysis: Partners in Retrosynthesis. Angew. Chem. Int. Ed. 2017, 56, 8942-8973. [CrossRef] [PubMed]

13. Müller, T.J.J. (Ed.) Metal Catalyzed Cascade Reactions; Springer: Berlin, Germany, 2006.

14. Lohr, T.L.; Marks, T. Orthogonal Tandem Catalysis. Nat. Chem. 2015, 7, 477-482. [CrossRef] [PubMed]

15. Verho, O.; Bäckvall, J.-E. Chemoenzymatic Dynamic Kinetic Resolution: A Powerful Tool for the Preparation of Enantiomerically Pure Alcohols and Amines. J. Am. Chem. Soc. 2015, 137, 3996-4009. [CrossRef] [PubMed]

16. Yang, B.; Zhu, C.; Qiu, Y.; Bäckvall, J.-E. Enzyme- and Ruthenium-Catalyzed Enantioselective Transformations of $\alpha$-Allenic Alcohols into 2,3-Dihydrofurans. Angew. Chem. Int. Ed. 2016, 55, 5568-5572. [CrossRef] [PubMed]

17. Palo-Nieto, C.; Afewerki, S.; Anderson, M.; Tai, C.-W.; Berglund, P.; Córdova, A. Integrated Heterogeneous Metal/Enzymatic Multiple Relay Catalysis for Eco-Friendly and Asymmetric Synthesis. ACS Catal. 2016, 6, 3932-3940. [CrossRef]

18. El-Sepelgy, O.; Alandini, N.; Rueping, M. Merging Iron Catalysis and Biocatalysis-Iron Carbonyl Complexes as Efficient Hydrogen Autotransfer Catalysts in Dynamic Kinetic Resolutions. Angew. Chem. Int. Ed. 2016, 55, 13602-13605. [CrossRef] [PubMed]

19. Görbe, T.; Gustafson, K.P.J.; Verho, O.; Kervefors, G.; Zheng, H.; Zou, X.; Johnston, E.V.; Bäckvall, J.-E. Design of a Pd(0)-CalB CLEA Biohybrid Catalyst and Its Application in a One-Pot Cascade Reaction. ACS Catal. 2017, 7, 1601-1605. [CrossRef]

20. Dixnuef, P.H.; Cadierno, V. (Eds.) Metal-Catalyzed Reactions in Water; Wiley-VCH: Weinheim, Germany, 2013.

21. Bornscheuer, U.T. Biocatalysis: Succesfull crossing boundaries. Angew. Chem. Int. Ed. 2015, 55, 4372-4373. [CrossRef] [PubMed]

22. Schmidt, S.; Castiglione, K.; Kourist, R. Overcoming the Incompatibility Challenge in Chemoenzymatic and Multi-Catalytic Cascade Reactions. Chem. Eur. J. 2018, 24, 1755-1768. [CrossRef] [PubMed]

23. Harald, G.; Hummel, W. Combining the 'two worlds' of chemocatalysis and biocatalysis towards multi-step one-pot processes in aqueous media. Curr. Opin. Chem. Biol. 2014, 19, 171-179. [CrossRef]

24. Trost, B.M. The atom economy-A search for synthetic efficiency. Science 1991, 254, 1471-1477. [CrossRef] [PubMed]

25. Trost, B.M.; Frederiksen, M.U.; Rudd, M.T. Ruthenium-Catalyzed Reactions-A Treasure Trove of Atom-Economic Transformations. Angew. Chem. Int. Ed. 2005, 44, 6630-6666. [CrossRef] [PubMed]

26. Sheldon, R.A. The E Factor: Fifteen years on. Green Chem. 2007, 9, 1273-1283. [CrossRef] 
27. Ríos-Lombardía, N.; Vidal, C.; Cocina, M.; Morís, F.; García-Álvarez, J.; González-Sabín, J. Chemoenzymatic one-pot synthesis in an aqueous medium: Combination of metal-catalysed allylic alcohol isomerisation-asymmetric bioamination. Chem. Commun. 2015, 51, 10937-10940. [CrossRef] [PubMed]

28. Ríos-Lombardía, N.; Vidal, C.; Liardo, E.; Morís, F.; García-Álvarez, J.; González-Sabín, J. From a Sequential to a Concurrent Reaction in Aqueous Medium: Ruthenium-Catalyzed Allylic Alcohol Isomerization and Asymmetric Bioreduction. Angew. Chem. Int. Ed. 2016, 55, 8691-8695. [CrossRef] [PubMed]

29. Rodríguez-Álvarez, M.J.; Ríos-Lombardía, N.; Schumacher, S.; Pérez-Iglesias, D.; Morís, F.; Cadierno, V.; García-Álvarez, J.; González-Sabín, J. Combination of Metal-Catalyzed Cycloisomerizations and Biocatalysis in Aqueous Media: Asymmetric Construction of Chiral Alcohols, Lactones, and $\gamma$-Hydroxy-Carbonyl Compounds. ACS Catal. 2017, 7, 7753-7759. [CrossRef]

30. Wang, Z.J.; Clary, K.N.; Bergman, R.G.; Raymond, K.N.; Toste, F.D. A supramolecular approach to combining enzymatic and transition metal catalysis. Nat. Chem. 2013, 5, 100-103. [CrossRef] [PubMed]

31. Lorenzo-Luis, P.; Romerosa, A.; Serrano-Ruiz, M. Catalytic isomerization of allylic alcohols in water. ACS Catal. 2012, 2, 1079-1086. [CrossRef]

32. Alhsten, N.; Bartoszewicz, A.; Martín-Matute, B. Allylic alcohols as synthetic enolate equivalents: Isomerisation and tandem reactions catalysed by transition metal complexes. Dalton Trans. 2012, 41, 1660-1670. [CrossRef] [PubMed]

33. García-Álvarez, J.; García-Garrido, S.E.; Crochet, P.; Cadierno, V. Metal-catalyzed isomerization of allylic and propargylic alcohols in aqueous media. Curr. Top. Catal. 2012, 10, 35-56.

34. Cahard, D.; Gaillard, S.; Renaud, J.-L. Asymmetric isomerization of allylic alcohols. Tetrahedron Lett. 2015, 56, 6159-6169. [CrossRef]

35. Li, H.; Mazet, C. Iridium-Catalyzed Selective Isomerization of Primary Allylic Alcohols. Acc. Chem. Res. 2016, 49, 1232-1241. [CrossRef] [PubMed]

36. Cadierno, V.; García-Garrido, S.E.; Gimeno, J.; Varela-Álvarez, A.; Sordo, J.A. Bis(allyl)-Ruthenium(IV) Complexes as Highly Efficient Catalysts for the Redox Isomerization of Allylic Alcohols into Carbonyl Compounds in Organic and Aqueous Media: Scope, Limitations, and Theoretical Analysis of the Mechanism. J. Am. Chem. Soc. 2006, 128, 1360-1370. [CrossRef] [PubMed]

37. Díez, J.; Gimeno, J.; Lledós, A.; Suárez, F.J.; Vicent, C. Imidazole Based Ruthenium(IV) Complexes as Highly Efficient Bifunctional Catalysts for the Redox Isomerization of Allylic Alcohols in Aqueous Medium: Water as Cooperating Ligand. ACS Catal. 2012, 2, 2087-2099. [CrossRef]

38. García-Álvarez, J.; Gimeno, J.; Suárez, F.J. Redox Isomerization of Allylic Alcohols into Carbonyl Compounds Catalyzed by the Ruthenium(IV) Complex $\left[\mathrm{Ru}\left(\eta^{3}: \eta^{3}-\mathrm{C}_{10} \mathrm{H}_{16}\right) \mathrm{Cl}\left(k^{2}-\mathrm{O}, \mathrm{O}-\mathrm{CH}_{3} \mathrm{CO}_{2}\right)\right]$ in Water and Ionic Liquids: Highly Efficient Transformations and Catalyst Recycling. Organometallics 2011, 30, $2893-2896$. [CrossRef]

39. Francos, J.; García-Garrido, S.E.; García-Álvarez, J.; Crochet, P.; Gimeno, J.; Cadierno, V. Water-tolerant bis(allyl)-ruthenium(IV) catalysts: An account of their applications. Inorg. Chim. Acta 2017, 455, 398-414. [CrossRef]

40. Kaluzna, I.A.; Rozzell, J.D.; Kambourakis, S. Ketoreductases: Stereoselective catalysts for the facile synthesis of chiral alcohols. Tetrahedron Asymmetry 2005, 16, 3682-3689. [CrossRef]

41. Cadierno, V.; Crochet, P.; Francos, J.; García-Garrido, S.E.; Gimeno, J.; Nebra, N. Ruthenium-catalyzed redox isomerization/transfer hydrogenation in organic and aqueous media: A one-pot tandem process for the reduction of allylic alcohols. Green Chem. 2009, 11, 1992-2000. [CrossRef]

42. Brown, C.J.; Miller, G.M.; Johnson, M.W.; Bergman, R.G.; Raymond, K.N. High-turnover supramolecular catalysis by a protected ruthenium(II) complex in aqueous solution. J. Am. Chem. Soc. 2011, 133, 11964-11966. [CrossRef] [PubMed]

43. Díaz-Rodríguez, A.; Lavandera, I.; Kanbak-Aksu, S.; Sheldon, R.A.; Gotor, V.; Gotor-Fernández, V. From Diols to Lactones under Aerobic Conditions using a Laccase/TEMPO Catalytic System in Aqueous Medium. Adv. Synth. Catal. 2012, 354, 3405-3408. [CrossRef]

44. Nakamura, I.; Yamamoto, Y. Transition-Metal-Catalyzed Reactions in Heterocyclic Synthesis. Chem. Rev. 2004, 104, 2127-2198. [CrossRef] [PubMed]

45. Alonso, F.; Belestkaya, I.P.; Yus, M. Transition-Metal-Catalyzed Addition of Heteroatom-Hydrogen Bonds to Alkynes. Chem. Rev. 2004, 104, 3079-3160. [CrossRef] [PubMed] 
46. Beller, M.; Seayad, J.; Tillack, A.; Jiao, H. Catalytic Markovnikov and anti-Markovnikov Functionalization of Alkenes and Alkynes: Recent Developments and Trends. Angew. Chem. Int. Ed. 2004, 43, 3368-3398. [CrossRef] [PubMed]

47. Patil, N.T.; Kavthe, R.D.; Shinde, V.S. Transition metal-catalyzed addition of C-, N- and O-nucleophiles to unactivated C-C multiple bonds. Tetrahedron 2012, 68, 8079-8146. [CrossRef]

48. Olson, A.R.; Hyde, J.L. The mechanism of lactone hydrolysis. J. Am. Chem. Soc. 1941, 63, $2459-2461$. [CrossRef]

49. Fukuda, Y.; Utimoto, K. Effective transformation of unactivated alkynes into ketones or acetals with a gold(III) catalyst. J. Org. Chem. 1991, 56, 3729-3731. [CrossRef]

50. Wang, W.; Xu, B.; Hammond, G.B. Efficient Synthesis of $\gamma$-Keto Esters through Neighboring Carbonyl Group-Assisted Regioselective Hydration of 3-Alkynoates. J. Org. Chem. 2009, 74, 1640-1643. [CrossRef] [PubMed]

51. Jeong, J.; Ray, D.; Oh, C.H. Cationic Gold-Catalyzed Regioselective Hydration of 1-Arylalkynes through Carbonyl Group Participation. Synlett 2012, 23, 897-902. [CrossRef]

52. Huang, L.; Arndt, M.; Gooßen, K.; Heydt, H.; Gooßen, L.J. Late Transition Metal-Catalyzed Hydroamination and Hydroamidation. Chem. Rev. 2015, 115, 2596-2697. [CrossRef] [PubMed]

53. Cox, R.A. Lactams in sulfuric acid. The mechanism of amide hydrolysis in weak to moderately strong aqueous mineral acid media. Can. J. Chem. 1998, 76, 649-656. [CrossRef]

54. De Vries, J.G.; Elsevier, S.J. (Eds.) Handbook of Homogeneous Hydrogenation; Wiley-VCH Verlag GmbH \& Co. KGaA: Weinheim, Germany, 2006.

55. Ertl, G.; Knözinger, H.; Schüth, F.; Weitkamp, J. (Eds.) Handbook of Heterogeneous Hydrogenation; Wiley-VCH Verlag GmbH \& Co. KGaA: Weinheim, Germany, 2008.

56. Wu, X.; Xiao, J. Hydrogenation and transfer hydrogenation in water. In Metal-Catalyzed Reactions in Water; Dixnuef, P.H., Cadierno, V., Eds.; Wiley-VCH: Weinheim, Germany, 2013.

57. Polshettiwar, V.; Asefa, T. (Eds.) Nanocatalysis: Synthesis and Applications; John Wiley \& Sons, Inc.: Hoboken, NJ, USA, 2013.

58. Schrittwieser, J.H.; Coccia, F.; Kara, S.; Grischek, B.; Kroutil, W.; d’Alessandro, N.; Hollmann, F. One-pot combination of enzyme and Pd nanoparticle catalysis for the synthesis of enantiomerically pure 1,2-amino alcohols. Green Chem. 2013, 15, 3318-3331. [CrossRef]

59. Sirasani, G.; Tong, L.; Balskus, E.P. A Biocompatible Alkene Hydrogenation Merges Organic Synthesis with Microbial Metabolism. Angew. Chem. Int. Ed. 2014, 53, 7785-7788. [CrossRef] [PubMed]

60. Royer, G.P.; Chow, W.-S.; Hatton, K.S. Palladium/polyethylenimine catalysts. J. Mol. Catal. 1985, 31 , 1-13. [CrossRef]

61. Coleman, D.R.; Royer, G.P. New hydrogenation catalyst: Palladium-poly(ethylenimine) "ghosts". Applications in peptide synthesis. J. Org. Chem. 1980, 45, 2268-2269. [CrossRef]

62. Agapakis, C.M.; Ducat, D.C.; Boyle, P.M.; Wintermute, E.H.; Way, J.C.; Silver, P.A. Insulation of a synthetic hydrogen metabolism circuit in bacteria. J. Biol. Eng. 2010, 4, 3-17. [CrossRef] [PubMed]

63. Kim, J.H.Y.; Jo, B.; Cha, H. Production of biohydrogen by recombinant expression of [NiFe]-hydrogenase in Escherichia coli. Microb. Cell Fact. 2010, 9, 54-63. [CrossRef] [PubMed]

64. Maegawa, T.; Akashi, A.; Sajiki, H. A Mild and Facile Method for Complete Hydrogenation of Aromatic Nuclei in Water. Synlett 2006, 1440-1442. [CrossRef]

65. Wedde, S.; Rommelmann, P.; Scherkus, C.; Schmidt, S.; Liese, A.; Gröger, H. An alternative approach towards poly- $\varepsilon$-caprolactone through a chemoenzymatic synthesis: Combined hydrogenation, biooxidations and polymerization without the isolation of intermediates. Green Chem. 2017, 19, 1286-1290. [CrossRef]

66. Bhorali, N.; Ganguli, J.N. Hydrogenation of Alkenes with Rhodium Nanoparticles Supported on SBA-15. Catal. Lett. 2013, 143, 276-281. [CrossRef]

67. Staudt, S.; Bornscheuer, U.T.; Menyes, U.; Hummel, W.; Gröger, E. Direct biocatalytic one-pot-transformation of cyclohexanol with molecular oxygen into $\varepsilon$-caprolactone. Enzym. Microb. Technol. 2013, 53, 288-292. [CrossRef] [PubMed]

68. Mallin, H.; Wulf, H.; Bornscheuer, U.T. A self-sufficient Baeyer-Villiger biocatalysis system for the synthesis of $\varepsilon$-caprolactone from cyclohexanol. Enzym. Microb. Technol. 2013, 53, 283-287. [CrossRef] [PubMed] 
69. Wang, J.; Li, K.; Zhou, X.; Han, W.; Wan, N.; Cui, B.; Wang, H.; Yuan, W.; Chen, Y. Asymmetric combinational "metal-biocatalytic system": One approach to chiral 2-substituted-tetrahydroquinoline-4-ols towards two-step one-pot processes in aqueous media. Tetrahedron Lett. 2017, 58, 2252-2254. [CrossRef]

70. Grubbs, R.H. (Ed.) Handbook of Metathesis; Wiley-VCH Verlag GmbH \& Co. KGaA: Weinheim, Germany, 2003.

71. Hoveyda, A.H.; Zhugralin, A.R. The remarkable metal-catalysed olefin metathesis reaction. Nature 2007, 450, 243-251. [CrossRef] [PubMed]

72. Grela, K. (Ed.) Olefin Metathesis: Theory and Practice; John Wiley \& Sons, Inc.: Hoboken, NJ, USA, 2014.

73. Lipshutz, B.H.; Ghorai, S. Transition-metal-catalyzed cross-couplings going green: In water at room temperature. Aldrichim. Acta 2008, 41, 59-72.

74. Burtscher, D.; Grela, K. Aqueous Olefin Metathesis. Angew. Chem. Int. Ed. 2009, 48, 442-454. [CrossRef] [PubMed]

75. Tomasek, J.; Schatz, J. Olefin metathesis in aqueous media. Green Chem. 2013, 15, 2317-2338. [CrossRef]

76. Tenbrink, K.; Seßler, M.; Schatz, J.; Gröger, H. Combination of Olefin Metathesis and Enzymatic Ester Hydrolysis in Aqueous Media in a One-Pot Synthesis. Adv. Synth. Catal. 2011, 353, 2363-2367. [CrossRef]

77. Scalacci, N.; Black, G.W.; Mattedi, G.; Brown, N.L.; Turner, N.J.; Castagnolo, D. Unveiling the Biocatalytic Aromatizing Activity of Monoamine Oxidases MAO-N and 6-HDNO: Development of Chemoenzymatic Cascades for the Synthesis of Pyrroles. ACS Catal. 2017, 7, 1295-1300. [CrossRef]

78. Denard, C.A.; Huang, H.; Bartlett, M.J.; Lu, L.; Tan, Y.; Zhao, H.; Hartwig, J.F. Cooperative Tandem Catalysis by an Organometallic Complex and a Metalloenzyme. Angew. Chem. Int. Ed. 2014, 53, 465-469. [CrossRef] [PubMed]

79. Gómez Baraibar, A.; Reichert, D.; Mügge, C.; Seger, S.; Gröger, H.; Kourist, R. A One-Pot Cascade Reaction Combining an Encapsulated Decarboxylase with a Metathesis Catalyst for the Synthesis of Bio-Based Antioxidants. Angew. Chem. Int. Ed. 2016, 55, 14823-14827. [CrossRef] [PubMed]

80. Bojarra, S.; Reichert, D.; Grote, M.; Gómez Baraibar, A.; Dennig, A.; Nidetzky, B.; Mügge, C.; Kourist, R. Bio-based $\alpha, \omega$-functionalized hydrocarbons from multi-step reaction sequences with bio- and metallo-catalysts based on the fatty acid decarboxylase OleTJE. ChemCatChem 2018. [CrossRef]

81. Polshettiwar, V.; Varma, R.S. Olefin Ring Closing Metathesis and Hydrosilylation Reaction in Aqueous Medium by Grubbs Second Generation Ruthenium Catalyst. J. Org. Chem. 2008, 73, 7417-7419. [CrossRef] [PubMed]

82. Ghislieri, D.; Green, A.P.; Pontini, M.; Willies, S.C.; Rowles, I.; Frank, A.; Grogan, G.; Turner, N.J. Engineering an Enantioselective Amine Oxidase for the Synthesis of Pharmaceutical Building Blocks and Alkaloid Natural Products. J. Am. Chem. Soc. 2013, 135, 10863-10869. [CrossRef] [PubMed]

83. Ghislieri, D.; Houghton, D.; Green, A.P.; Willies, S.C.; Turner, N.J. Monoamine Oxidase (MAO-N) Catalyzed Deracemization of Tetrahydro- $\beta$-carbolines: Substrate Dependent Switch in Enantioselectivity. ACS Catal. 2013, 3, 2869-2872. [CrossRef]

84. Köhler, V.; Wilson, Y.M.; Durrenberger, M.; Ghislieri, D.; Churakova, E.; Quinto, T.; Knorr, L.; Haussinger, D.; Hollman, F.; Turner, N.J.; et al. Synthetic cascades are enabled by combining biocatalysts with artificial metalloenzymes. Nat. Chem. 2012, 5, 93-99. [CrossRef] [PubMed]

85. Heath, R.S.; Pontini, M.; Bechi, B.; Turner, N.J. Development of an R-Selective Amine Oxidase with Broad Substrate Specificity and High Enantioselectivity. ChemCatChem 2014, 6, 996-1002. [CrossRef]

86. Wakamatsu, H.; Blechert, S. A Highly Active and Air-Stable Ruthenium Complex for Olefin Metathesis. Angew. Chem. Int. Ed. 2002, 41, 794-796. [CrossRef]

87. Van Veldhuizen, J.J.; Garber, S.B.; Kingsbury, J.S.; Hoveyda, A.H. A Recyclable Chiral Ru Catalyst for Enantioselective Olefin Metathesis. Efficient Catalytic Asymmetric Ring-Opening/Cross Metathesis in Air. J. Am. Chem. Soc. 2002, 124, 4954-4955. [CrossRef] [PubMed]

88. Hischer, T.; Steinsiek, S.; Ansorge-Schumacher, M.B. Use of polyvinyl alcohol cryogels for the compartmentation of biocatalyzed reactions in non-aqueous media. Biocatal. Biotransform. 2009, 24, 437-442. [CrossRef]

89. Meldal, M.; Christensen, C.; Tornøe, C.W. Peptidotriazoles on Solid Phase: [1,2,3]-Triazoles by Regiospecific Copper(I)-Catalyzed 1,3-Dipolar Cycloadditions of Terminal Alkynes to Azides. J. Org. Chem. 2002, 67, 3057-3064. [CrossRef] 
90. Sharpless, K.B.; Fokin, V.V.; Green, L.G.; Rostovtset, V.V. A stepwise huisgen cycloaddition process: Copper(I)-catalyzed regioselective "ligation" of azides and terminal alkynes. Angew. Chem. Int. Ed. 2002, 41, 2708-2711. [CrossRef]

91. Kolb, H.C.; Finn, M.G.; Sharpless, K.B. Click Chemistry: Diverse Chemical Function from a Few Good Reactions. Angew. Chem. Int. Ed. 2001, 40, 2004-2021. [CrossRef]

92. Campbell-Verduyn, L.S.; Szymánski, W.; Postema, C.P.; Dierckx, R.A.; Elsinga, P.H.; Janssen, D.B.; Feringa, B.L. One pot "click" reactions: Tandem enantioselective biocatalytic epoxide ring opening and [3+2] azide alkyne cycloaddition. Chem. Commun. 2010, 46, 898-900. [CrossRef] [PubMed]

93. Szymánski, W.; Postema, C.P.; Tarabiono, C.; Berthiol, F.; Campbell-Verduyn, L.; de Wildeman, S.; de Vries, J.G.; Feringa, B.L.; Janssen, D.B. Combining Designer Cells and Click Chemistry for a One-Pot Four-Step Preparation of Enantiopure $\beta$-Hydroxytriazoles. Adv. Synth. Catal. 2010, 352, 2111-2115. [CrossRef]

94. Cuetos, A.; Bisogno, F.R.; Lavandera, I.; Gotor, V. Coupling biocatalysis and click chemistry: One-pot two-step convergent synthesis of enantioenriched 1,2,3-triazole-derived diols. Chem. Commun. 2013, 49, 2625-2627. [CrossRef] [PubMed]

95. Tang, L.; van Hylckama Vlieg, J.E.; Lutje Spelberg, J.H.; Fraaije, M.W.; Janssen, D.B. Improved stability of halohydrin dehalogenase from Agrobacterium radiobacter AD1 by replacement of cysteine residues. Enzym. Microb. Technol. 2002, 30, 251-258. [CrossRef]

96. Miyaura, N. (Ed.) Cross-Coupling Reactions: A Practical Guide; Springer: Berlin, Germany, 2002.

97. De Meijere, A.; Diederich, F. (Eds.) Metal-Catalyzed Cross-Coupling Reactions, 2nd ed.; Wiley-VCH: Weinheim, Germany, 2004.

98. Nishihara, Y. (Ed.) Applied Cross-Coupling Reactions; Springer: Berlin, Germany, 2013.

99. Shaughnessy, K.H. Cross-coupling reactions in aqueous media. In Palladium-Catalyzed Coupling Reactions: Practical Aspects and Future Developments; Molnár, Á., Ed.; Wiley-VCH Verlag GmbH \& Co. KGa: Weinheim, Germany, 2013.

100. Burda, E.; Hummel, W.; Gröger, H. Modular Chemoenzymatic One-Pot Syntheses in Aqueous Media: Combination of a Palladium-Catalyzed Cross-Coupling with an Asymmetric Biotransformation. Angew. Chem. Int. Ed. 2008, 47, 9551-9554. [CrossRef] [PubMed]

101. Ahmed, S.T.; Parmeggiani, F.; Weise, N.J.; Flitsch, S.L.; Turner, N.J. Chemoenzymatic Synthesis of Optically Pure L- and D-Biarylalanines through Biocatalytic Asymmetric Amination and Palladium Catalyzed Arylation. ACS Catal. 2015, 5, 5410-5413. [CrossRef]

102. Frese, M.; Schnepel, C.; Minges, H.; Voß, H.; Feiner, R.; Sewald, N. Modular Combination of Enzymatic Halogenation of Tryptophan with Suzuki-Miyaura Cross-Coupling Reactions. ChemCatChem 2016, 8, 1799-1803. [CrossRef]

103. Latham, J.; Henry, J.-M.; Sharif, H.H.; Menon, B.R.K.; Shepherd, S.A.; Greaney, M.F.; Micklefield, J. Integrated catalysis opens new arylation pathways via regiodivergent enzymatic C-H activation. Nat. Commun. 2016, 7, 11873. [CrossRef] [PubMed]

104. Boffi, A.; Cacchi, S.; Ceci, P.; Cirilli, R.; Fabrizi, G.; Prastaro, A.; Niembro, S.; Shafir, A.; Vallribera, V. The Heck Reaction of Allylic Alcohols Catalyzed by Palladium Nanoparticles in Water: Chemoenzymatic Synthesis of (R)-(-)-Rhododendrol. ChemCatChem 2011, 3, 347-353. [CrossRef]

105. Fuchs, M.; Schober, M.; Pfeffer, J.; Kroutil, W.; Birner-Gruenberger, R.; Faber, K. Homoallylic Alcohols via a Chemo-Enzymatic One-Pot Oxidation-Allylation Cascade. Adv. Synth. Catal. 2011, 353, 2354-2358. [CrossRef]

106. Sonoike, S.; Itakura, T.; Kitamura, M.; Aoki, S. One-pot Chemoenzymatic Synthesis of Chiral 1,3-Diols Using an Enantioselective Aldol Reaction with Chiral $\mathrm{Zn}^{2+}$ Complex Catalysts and Enzymatic Reduction Using Oxidoreductases with Cofactor Regeneration. Chem. Asian J. 2012, 7, 64-74. [CrossRef] [PubMed]

107. Suzuki, A. Synthetic studies via the cross-coupling reaction of organoboron derivatives with organic halides. Pure Appl. Chem. 1991, 63, 419-422. [CrossRef]

108. Negishi, E.-I. (Ed.) Handbook of Organopalladium Chemistry for Organic Synthesis; Wiley-Interscience: Hoboken, NJ, USA, 2002; Volume 1.

109. Hall, G. (Ed.) Boronic Acids. Preparation and Application in Organic Synthesis and Medicine; Wiley-VCH Verlag GmbH \& Co. KGa: Weinheim, Germany, 2006.

110. Turner, N.J. Ammonia lyases and aminomutases as biocatalysts for the synthesis of $\alpha$-amino and $\beta$-amino acids. Curr. Opin. Chem. Biol. 2011, 15, 234-240. [CrossRef] [PubMed] 
111. Vedha-Peters, K.; Gunawardana, M.; Rozzell, J.D.; Novick, S.J. Creation of a Broad-Range and Highly Stereoselective D-Amino Acid Dehydrogenase for the One-Step Synthesis of D-Amino Acids. J. Am. Chem. Soc. 2006, 128, 10923-10929. [CrossRef] [PubMed]

112. Frese, M.; Sewald, N. Enzymatic Halogenation of Tryptophan on a Gram Scale. Angew. Chem. Int. Ed. 2015, 54, 298-301. [CrossRef] [PubMed]

113. Mizoroki, T.; Mori, K.; Ozaki, A. Arylation of olefins with aryl iodine catalyzed by palladium. Bull. Chem. Soc. Jpn. 1971, 44, 581. [CrossRef]

114. Heck, R.F.; Nolley, J.P. Palladium-catalyzed vinylic hydrogen substitution reactions with aryl, benzyl, and styryl halides. J. Org. Chem. 1972, 37, 2320-2322. [CrossRef]

115. Beller, M.; Fischer, H.; Kühlein, K.; Reisinger, C.P.; Hermann, W.A. First palladium-catalyzed Heck reaction with efficient colloidal catalyst systems. J. Organomet. Chem. 1996, 520, 257-259. [CrossRef]

116. Oestreich, M. (Ed.) The Mizoroki-Hech reaction; John Wiley \& Sons: Chichester, UK, 2009.

117. Baig, R.B.N.; Varma, R.S. Nanocatalysis in water. In Metal-Catalyzed Reactions in Water; Dixnuef, P.H., Cadierno, V., Eds.; Wiley-VCH: Weinheim, Germany, 2013.

118. Shaughnessy, K.H. Metal-catalyzed cross-coupling of aryl halides to form C-C bonds in aqueous media. In Metal-Catalyzed Reactions in Water; Dixnuef, P.H., Cadierno, V., Eds.; Wiley-VCH: Weinheim, Germany, 2013.

119. Barbier, P. Synthèse du diméthylhepténol. C. R. Acad. Sci. 1899, 128, 110-111.

120. Wakefield, B.J. Comprehensive Organometallic Chemistry; Chapter 44; Pergamon: Oxford, UK, 1982 ; Volume 7.

121. García-Álvarez, J.; Hevia, E.; Capriati, V. Reactivity of Polar Organometallic Compounds in Unconventional Reaction Media: Challenges and Opportunities. Eur. J. Org. Chem. 2015, 31, 6779-6799. [CrossRef]

122. Li, C.-J.; Chan, T.H. Organometallic Reactions in Aqueous Media. 2. Convenient Synthesis of Methylenetetrahydrofurans. Organometallics 1991, 10, 2548-2549. [CrossRef]

123. Hudlucky, M. Oxidations in Organic Chemistry; ACS Monograph Series; American Chemical Society: Washington, DC, USA, 1990.

124. Mutti, F.G.; Orthaber, A.; Schrittwieser, J.H.; de Vries, J.G.; Pietschnig, R.; Kroutil, W. Simultaneous iridium catalysed oxidation and enzymatic reduction employing orthogonal reagents. Chem. Commun. 2010, 46, 8046-8048. [CrossRef] [PubMed]

125. Haak, R.M.; Berthiol, F.; Jerphagnon, T.; Gayet, A.J.A.; Tarabiono, C.; Postema, C.P.; Ritleng, V.; Pfeffer, M.; Janssen, D.B.; Minnaard, A.J.; et al. Dynamic Kinetic Resolution of Racemic $\beta$-Haloalcohols: Direct Access to Enantioenriched Epoxides. J. Am. Chem. Soc. 2008, 130, 13508-13509. [CrossRef] [PubMed]

126. Sato, H.; Hummel, W.; Gröger, H. Cooperative Catalysis of Noncompatible Catalysts through Compartmentalization: Wacker Oxidation and Enzymatic Reduction in a One-Pot Process in Aqueous Media. Angew. Chem. Int. Ed. 2015, 54, 4488-4492. [CrossRef] [PubMed]

127. Runge, M.B.; Mwangi, M.T.; Miller, A.L., II; Perring, M.; Bowden, N.B. Cascade Reactions Using $\mathrm{LiAlH}_{4}$ and Grignard Reagents in the Presence of Water. Angew. Chem. Int. Ed. 2008, 47, 935-939. [CrossRef] [PubMed] 